AMAZONIA - DEMOGRAFIA Vol. 1-No. 1 pág.9-58

\title{
POBLACIONES NATIVAS DE LA AMAZONIA PERUANA
}

Luis M. URIARTE

L'auteur a donné ici une vue panoramique des 64 (67) ethnies aborigines de l'Amazonie Pérouvienne, leurs emplacements, les courbes démographiques, les tendences de l'identité éthnique, etc. On a presenté aussi, la situation particuliére de chaque groupe (éducation, santé, logement, etc.) et un bilan des "fronts de développement" économiques, politiques et culturels.

The author presents a panoramic view of the 64 (perhaps 67) clearly identifi able ethnic groups in the Amazon region of Perú. He offers detailes information concerning population, demographic tendencies, degree of ethnic self identity and interaction with non-indigenous populations. In addition the author provides valuable data concerning such aspects as housing, education, health and land's legal ownwership. Lastly he offers detailed description of the economic, political and socio-cultural expansion of advancing civilization encroaching upon these ethnic groups.

In allgemeiner und detaillierter Form werden 64 (order 67) Indianerstaemme des peruanischen Urwaldes dargestelt. Aufgezeigt werden: Habitat, Demographie, Grade und TEndenzen der Ethnischen Identitaet, etc. und die spezielle Situacion jeder Gruppe (Wohnbedinggungen, Erziehungsgrad, Gesundheitsszustand, etc.) Die expansorischen Grenzen, im oekonomische, politische und kulturellen, werden dargelegt.

\footnotetext{
* (Parte de este estudio inédito fue presentado como Documento de Trabajo ante el "l ternational Conference of Indigenous People" celebricic en Port Alberni, Vancouver Island, British Columbia, Canada Octubre 1975).
} 
Trataré de presentar sumariamente, primero, una visión global de las Comunidades $\mathrm{Na}$ tivas (1) haciendo énfasis en el contexto regional de la Sociedad Dominante-Envolvente. Analizaré cómo los frentes de expansión, segmentos de la Comunidad Nacional, contfrontan a los Grupos Tribales en la Selva. En segundo lugar, intentaré presentar la situación especffica de cada uno de los Grupos Etno-Lingüisticos. Finalmente recogeré aquellos elementos que considero más relevantes para una diagnosis correcta de la situación y al mismo tiempo alertar sobre el peligro serio que atenta, en mi opinión, contra una política etnicamente autóctona en el Perú Amazónicu.

El tema es excesivamente amplio. Pero considero valioso compilar en un solo trabajo esta documentación. Algunos datos como especificaré en su momento son tentativos. Espero que ulteriores estudios verifiquen unos, modifiquen otros, y/o profundicen todos.

\section{PARTE I : VISION GENERAL}

1. Datos Generales : EI Perú tiene una extensión de 1'282,215.60 Km2. que abarcan tres regiones ecológica y socio-culturalmente diversas : Costa, Sierra y Selva. La Cordillera Andina recorre el país de norte a sur separando las regiones de costa (vertiente del Pacifico) y Selva (vertiente del Atlántico).

En la Región de Selva también por razones ecológicas, económicas, demográficamigratorias y recientemente por razones "legales" (2) conviene distinguir entre Ceja de Selva y Selva Baja. Ambas sub-regiones selváticas comprenden una extensión aproximada de $700,000 \mathrm{Km} 2$. y es el habitat de las Poblaciones nativas que aqui nos ocupan.

El último Censo Nacional de 1972 arroja una población de 14'121,564 habitantes para todo el país (3) de los cuales escasamente dos millones habitan las regiones de Selva y Ceja de Selva. Conviene advertir desde el inicio, que los datos oficiales compilados por la Oficina Nacional de Estadistica y Censos (ONEC) presentan serias limitaciones en lo que se refiere a la Amazonía y muy especialmente en lo referente a Grupos Nativos.

(1) "Comunidades Nativas" es el término Legal usado en el Decreto Ley No. 20653 del 24 de junio de 1974, para referirse a las Etnias Indígenas de la Amazonia Peruana.

EI Decreto Supremo No. 0585 - 75 . AG del 5 de junio de 1975 establecib legal y definitivamente los Irmites entre Sierra, Ceja de Selva y Selva Baja. EI citado Decreto Supremo definio de manera operativa, descriptiva y funcional la Primera Disposición Complementaria y Transitoria del Decreto Ley No. 20653 del 24 de junio de 1974. 
Fuentes más especializadas (4) en los Grupos Etno-lingüísticos, aunque también exhiben limitaciones, arrojan una población aproximada de 225,000 Nativos. Carecemos en la actualidad de un censo fidedigno $v$ exacto; sin embargo con los datos que ahora disponemos $y$ los controles muestreados que realicé durante 1974, me llevan a señalar como tope máximo 235,000 y límite mínimo 205,000 para la Población Nativa.

Mi estimado actual es de 212,495 nativos en la Selva Peruana.

2. Los Grupos Nativos agrupados en 64 (posiblemente 67) Grupos y/o sub-grupos Etnolingüísticos presentan una vasta riqueza cultural así como una notable diversidad. Esta diversidad (a pesar de formar y compartir un área cultural) proviene de numerosos factores de los cuales destacaremos aquí solamente cuatro: la lengua, la composición de mográfica, la contigüidad en la ocupación territorial y finalmente el grado de contacto $\mathrm{y} / \mathrm{o}$ interacción con la Comunidad Nacional.

2.1 Aunque la clasificación lingüística de algún Grupo sea tentativa (como es el caso de la familia Harak'mut - Amarakaeri, Wachipaeri, etc. - del Madre de Dios que claramente no es Arawak como hasta ahora se había considerado) (5), la panorámica etno-lingüística es la siguiente : los Grupos Etno-lingüísticos pertenecen a dos Phylum Lingüísticos, el GE-PANO-CARIBE y el ANDINO ECUATORIAL.

El Phylum Ge-Pano-Caribe abarca dos Troncos linguísticos que son el Macro-Caribe y el Macro-Pano. El Tronco Macro-Caribe en el Perú Amazónico comprende una sola Familia Lingúística denominada Peba-Yaguana, a la que pertenecen cinco Grupos Etnicos: Yagua, Witoto-Muruí, Witoto-Muinane, Bora y Ocaina-Andoque.

El Tronco Macro-Pano, por su parte, abarca dos Familias Lingüísticas que son la Familia Pano y la Tacana. La Familia Pano, la más extensa y representada en el Perú Amazónico, comprende 15 (posiblemente 18) Grupos Etnicos: Amahuaca, Capanahua, Cashibo, Shipibo, Conibo, Cacataibo, Cashinahua, Yaminahua, Sharanahua, Mastanahua, Marinahua, Chaninahua, Matsé (Mayoruna), Iskobákebu (Isconahua), Capishto (Grillos) y posiblemente los Remo, Maruno y los Mayo-Pisahuas (6). La Familia Tacana comprende un solo Grupo Etnico en Perú, a saber los Esa'exa (7).

(4) SINAMOS - Centro de Estudios de Participación Popular: la dirección General de Organizaciones Rurales y diversos ORAMS y OZAMS dependientes de ONAM y SINAMOS, etc. Misiones Catblicas, ILV y datos de primera mano recolectados en 1974 - 75 (Cfr. Uriarte: Survey Amazónico 1975).

(5) Comunicación personal de Thomas Moore. Ver también la corrección de Shell y Wise hecha en 1975 a su publicación sobre Grupos Idiomáticos del Perá, 1971. Así mismo ver Van der Eynde 1972 y material inédito del CILA.

Estos tres Grupos aparecen en la literatura, incluso actual; sin embargo yo no he podido constatar empiricamente en el campo (región que se menciona en la literatura como habitada por esos grupos) la existencia de cualquiera de esos tres grupos. Aunque en las zonas mismas los informantes hablan de esos grupos, yo no he encontrado ningún informante que realmente haya entrado en contacto directo o indirecto con algún Remo, Marubo o Mayo-Pisahua.

(7) Vulgarmente $y$ aún en la literatura antropológica y lingǘstica son conocidos como "Huarayos". Sin embargo ese término es sumamente despectivo, y ofensivo al Grupo Esa exa y conduce a confusión con el Grupo Guarayo de filiación lingüistica, Tupi que habita el oriente Boliviano y es claramente independiente ode los Esa' exa. 
El Phylum Andino-Ecuatorial, en la Amazonía Peruana, presenta una mayor diversidad. Comprende tres Troncos Lingüísticos que son el Andino, el Macro-Tucano y el Ecuatorial.

El Tronco Andino abarca cuatro Familias Lingüísticas : 1) La Zaparoana que comprende cuatro Grupos Etnicos: Andoa (Shimigae), Iquito, Arabela y Záparo (Vacacocha o Aushiri ?). 2) La Familia Cahuapana con tres Grupos : Chayahuita, Jeberino, Balsapuertino. 3) La Familia Quechua con seis Grupos : Lamisto (Sanmartiniano), Inga (R. Corrientes), Quichua-Maca (Napo), Quichua-Canelo (Napo), Quichua-Yumbo (Napo), Quichua-Santarrosino (Madre de Dios). 4) Finalmente; dentro del Tronco Andino, tenemos la Familia Jibaroana que incluye los siguientes Grupos: Aguaruna, Huambisa, Achual, Jívaro (del R. Corrientes), Candoshi-Shapra y Candoshi-Murato. Es decir, seis Grupos Etnicos.

El Tronco Macro-Tucano, por su parte, abarca en la Amazonía Peruana dos Familias lingüísticas que son la Tucanoana y la Shimacu. Dentro de la primera constatamos cuatro Grupos Etnicos : Koto (Orejón), Secoya-Angotere, SecoyaPiojé y. Ticuna. La Familia Shimacu por el contrario solamente incluye al Grupo Urarina (Cimarrón o Shimacu).

Finalmente el Tronco Ecuatorial abarca tres Familias Lingüísticas: Arawak, Tupi-Guarani y (tentativamente, pues es posible que ulteriores estudios demuestren que ni siquiera deba clasificarse dentro del Tronco Ecuatorial), la Familia Harak' mut. La Familia Arawak comprende numerosos e importantes Grupos Etnicos : Amuesha, Ashaninka (Campa), Gran Pajonalino (Campa), Nomatsiguenga (Campa), Maghiguenga, Piro (y sub-grupo Manchineri), Culina y Chamicuro. Es decir, nueve Grupos. La Familia Tupi-Guarani abarca tres Grupos : Los Cocama, Cocamilla y Omagua. $Y$ finalmente la familia que hemos denominado Harak'mut (8) incluye al menos siete Grupos Etnicos: Amarakaeri, Wachipaeri, Arasaeri, Toyoeri, Sirineri (Sapiteri), Kisambaeri (Pukirieri), Iñapari.

2.2 Un segundo factor al considerar la diversidad entre los Grupos, es la composición demográfica (densidad poblacional). El spectrum varía desde la "nación Ashaninka (Campa)" con una población aproximada de 45,000; la "nación Aguaruna" con 22,000; la "nación Machiguenga" con aproximadamente 12,000; la "nación Piro o Amuesah" con unos 5,000 respectivamente; el Grupo Bora con escasamente 600 nativos; o el Grupo Arabela con solamente 180 miembros en la actualidad.

No es este el momento de elaborar el tema, pero sí de enfatizar la importancia capital que tiene la composición demográfica de un grupo para que los sistemas tradicionales de endogamia, parentesco, asentamiento, residencia y todo el sistema ceremonial puedan'funcionar. $Y$ por tanto la imposibilidad de supervivencia (como Grupo Etnico e incluso como Comunidad parlante), si la población se reduce más allá de cierto límite (9).

2.3 El tercer factor está directamente relacionado con la ocupación territorial. En la Amazonía Peruana, encontramos Grupos Etnicos que ocupan y mantienen una zona compacta, contigua, sin infiltraciones significativas de colonos (i. e. asen-

(8) El término Harak'but (o Harakmbet o Aratmbut) parece haber sido acuñado por el antropólogo Thomas Moore $y$ ha sido recogido subsecuentemente por Shell y Wise del ILV. 
tamientos de "civilizados-mozos-ribereños", etc.). Así pol ejemplo los Matsés (Mayorunas), los Achual, los Aguaruna del Cenepa, etc.

Sin embargo, encontramos otros Grupos enclavados en zonas con abundante población no-Nativa. Así por ejemplo : los Ashaninka (Campa) del Perené, los Shipibo y Conibo del Ucayali, los Amuesha, Piro, y especialísimamente los Cocama y Cocamilla.

Finalmente, en la actualidad, encontramos Grupos atomizados en Comunidades distantes e inconexas. Así por ejemplo, los Witoto, Bora, Yagua, etc. Hay también una serie de Grupos Etnicos (que especificaré posteriormente al hablar de la configuración geo-política) que se encuentran separados $\mathrm{y}$ divididos por fronteras internacionales entre Ecuador, Colombia, Brasil, Bolivia y Perú.

2.4 El cuarto factor está directamente relacionado con el grado y tipo de interacción del Grupo Etnico vis-avis los diferentes frentes de expansión provenientes de la Sociedad Nacional.

Así encontramos Grupos en situación de aislamiento, sin contacto significativo con los intermediarios (de tipo económico, político y/o cultural) de la sociedad envolvente. Los Grupos que se encuentran en situación de "aislamiento", son de dos categorías: a)- Aislamiento, sin previo contacto significativo, como los Matsés, y los sub-grupos Machiguenga, Aguaruna, Ashaninka, Amahuaca, Murato, etc. y posiblemente los Capishto (Grillos), Remo y Mayo-Pisahua. b)- Aislamiento post-contacto al que rehuyeron. Este parece ser el caso de los Secoya, U. rarina o Shimacu, Arabela, sub-grupos Ashaninka, Achual, etc.

Otros Grupos Etnicos se encuentran en situación de contacto esporádico y/o poco intenso. En esta categoría encontramos a los Candoshi, Jíbaros del TigreCorrientes, Urarina, etc.

Existen no obstante, una serie de Grupos sometidos a una interacción permanente e intensa pero con efecto diverso. a)- Los que ante el contacto han efectuado un proceso de "acomodación" manteniendo sin embargo su identidad étnica básica, su lengua y en conjunto sus sistemas tradicionales aunque "acomodados" a la nueva situación. Así encontramos a los Lamisto, Piro, sub-grupos Aguaruna, Ashaninka, Shipibo, Conibo, etc. b)- Los que se han "incardinado" (no "integrado") en la sociedad dominante, sufriendo sin embargo un proceso de desintegración étnica, pérdida (uso al menos) de la lengua, destribalización. En esta categoria encontramos a los Cocama, Iñapari, Omagua, Jeberino, sub-grupos Amuesha, Yagua, Quichua-Santarrosino, etc. (10).

(10) Sin embargo, conviene observar que carecemos de estudios etnográficos serios sobre estos Grupos para poder evaluar (más alla de ciertas apariencias externas y/o apreciaciones etnocentricas) el grado real de desintegración étnica. Los indicios de endogamia y asentamiento segregado de Cocamas por ejemplo en Iquitos, Pucallpa, etc. en "Pueblos Jovenes" (eufemismo actual para designar a las antiguas "barriadas" " "Favelas") nos llevan a ser cautos al hablar tanto de "destribalizacion" de das" o "Favelas") nos lievan a ser cautos al hablar "absorción" en la comunidad nacional. 
Es importante mencionar en este contexto dos datos : primero, que numerosos grupos que aparecían en la literatura (11) hoy ya no existen, o fueron drásticamente reducidos; segundo, que en algunos Grupos, actualmente se perciben indicios ae cierta "revitalización étnica", como en algunas Comunidades Ashaninka, Shipibo, Conibo, Aguaruna, Quichua del Napo, Chayahuita, etc. (12).

Para concluir esta parte quisiera recalcar que los 64 (posiblemente 67) Grupos etno-lingüisticos de la selva peruana presentan una notable variedad y una problemática específica que debe tenerse en cuenta $-y$ que debe ser analizada en cada caso- antes de hacer generalizaciones $y / 0$ recomendaciones. $Y \sin$ embargo, sin negar lo anterior, observamos una notable uniformidad en las presiones que afectan en mayor o menor grado a los diferentes Grupos Nativos.

Por ello creo conveniente tratar, si bien sumariamente, el contexto global que enmarca las relaciones (y presiones) entre la Sociedad Nacional y la Región Amazónica; y consecuentemente . de manera especial, las Etnias-Indigenas.

\section{Configuración geográfica y demográfica :}

3.1 Desde la "Conquista" Española, pasando por la Colonia, la época Republicana y casi hasta hace 10 años, la selva peruana con excepción de los grandes rios se mantuvo altamente aislada de la vida nacional. Por las condiciones geográficas y ecológicas de la Amazonía y por la gran barrera Andina, la selva permaneció desconectada de la metrópoli, Lima. Es un dato histórico significativo que el descubrimiento del Amazonas por Orellana se efectuara desde el Ecuador por el Río Napo; que las Misiones Jesuíticas de Maynas se gobernaran desde Quito y que la explotación del caucho (aún en pleno apogeo de 1884 a 1914) se efectuara por el Amazonas hacia el Atlántico (13).

Sin embargo, ésta situación de aislamiento tradicional, está siendo alterada radicalmente en la actualidad por los siguientes factores:

1. Se han construído o están construyendo diez carreteras de "penetración" que atravesando la Sierra unen la Costa con la Selva:

(11) Espinosa 1960: "Archivo Agustiniano", Vol LIV, No. 160; pág. 46 a 49. También Espinosa 1949 - 50: "Pueblos Indigenas de la Amazonía Peruana" Madrid, Tomo II, pág. 541 a 550 y Tomo III, pág. 510 a 521 . También presenta datos significativos Corial G. Juan 1942: “El Hombre del Amazonas y Ensayo Monográfico de Loreto", Lima; en la pág. 11 presenta "las tribus conocidas y clasificadas" segúnel autor. Finalmente entre otros, Fuentes, Hildebrando 1908 ex-prefecto del Departamento de Loreto quien publica dos tomos: "Loreto, apuntes geográficos, históricos, estadísticos, políticos y sociales", Lima. Es particularmente interesante el tomo II, pág. 251 para nuestro tema.

La "revitalización étnica" que se percibe en los últimos cinco años ha sido fundamentalmente debida a diversos "Congresos Indigenas" -intra e inter-tribales- que han tenido algunos Grupos Nativos. Si bien tales Congresos han sido en gran parte promovidos por agentes de SINAMOS y por ciertos misioneros católicos (por ejemplo G. Villeneuve en el Ucayali; J. M. Nercier en el Napo; J. Purón en el Santia go, etc.) han dejado un cierto impacto político y despertado autoestima y cohesión étnica dentro de esos Grupos que han tomado conciencia e iniciado mecanismos de cohesion intertribal.

(13) También es un dato histórico el que los Misioneros Franciscanos con base en Ocopa (a unos treinta Kms. de Huancayo) penetraron la Selva Amazónica, pero su in. flujo se concentro especialmente en la ceja de Selva o Selva Alta, particularmente, en los Grupos Ashaninka, Amuesha y Piro. 
Carretera No. 1 : Chiclayo-Olmos-Pto. América, punto navegable del Río Marañón, atraviesa todo el territorio de los Aguaruna y Huambisa.

Carretera No. 2 : Chiclayo-Ingenio-Rioja-Moyobamba-Yurimaguas, punto navegable del Río Huallaga; está casi totalmente construída y discurre en parte por territorio tribal de los Aguaruna, Lamisto, Chayahuita.

Carretera No. 3 : Chimbote-Sihuas-Uchiza. Esta vía se encuentra más atrasada en su construcción.

Carretera No. 4 : Lima-Tingo María-Pucallpa, importante puerto fluvial en el Río Ucayali que une centralmente gran parte de la Amazonía (no sólo peruana) con la Sierra y la Costa. Esta ruta que une el Atlántico con el Pacfficoessin duda alguna la carretera de penetración más importante; afecta directamente a numerosos Grupos Nativos : los Cashibo, Shipibo, Conibo, Cocama, Cocamilla; e indirectamente afecta a todos los Grupos de la Selva Baja.

Carretera No. 5 : Lima-Cerro de Pasco-Huánuco-Tingo María-Juanjuy-Tarapoto. Tiene un ramal hacia Pozuzo que afecta a los Amuesha y Lamisto.

Carretera No. 6 : Lima-San Ramón-Villa Rica-Pto. Bermález a un punto navegable del Río Pachitea; afecta a los Amuesha y Campa. Cuenta con un ramal de La Merced a Oxapampa y Pozuzo.

Carretera No. 7 : Lima-Satipo con dos rutas, una por La Merced y el valle del Perené hasta Satipo y otra por Concepción, Ocopa en las cercanías de Huancayo; está proyectada hasta Atalaya en el Río Ucayali. Los Grupos afectados son los Ashaninka, directamente; y Piro, Amahuaca, Yaminahua y otros muchos, indirectamente.

Carretera No. 8 : Cusco-Quillabamba, hasta pasado el Pongo de Mainique donde el Rio Urubamba es navegable; afecta directamente al Grupo Machiguenga (en Chirumbia, Koriboni, etc.)

Carretera No. 9 : Cusco-Paucartambo-Alto Madre de Dios, terminada ya hasta Shintuya punto navegable del Madre de Dios, afecta directamente a los Amarakaeri, Wachipaeri, etc.; también a los Piro de Diamante. La carretera está proyectada hasta Iberia e Iñapari pasando por el Manú con lo que afectará además a los Yaminahua y Amahuaca del Río Piedras y a los Marinahua del Río Acre.

Carretera No. 10 : Cusco-Quince Mil-Pto. Maldonado sobre el Río Madre de Dios, ya terminada, afecta directamente a los Arasaeri, Kisambaeri, Sapiteri, Toyoeri y Esa'exa. También ésta carretera está proyectada hasta Iberia e Iñapari, afectando así a los Marinahua del Acre, Quichua Santarrosino, Amahuaca del Pariamanú $y$ de un modo indirecto a los Manchineri del Río Yacu y los Yaminahua del Chandless.

Estas diez carreteras de penetración estarán (en algunas zonas ya están) enlazadas por la "Carretera Marginal" que recorre toda la Ceja de Selva paralelamente a la Carretera Panamericana de la Costa.

2. Finalmente, tanto las comunicaciones fluviales (la Compañía Peruana de Va- 
pores recientemente creada y otras), como el transporte aéreo (aviones "Vuelos-Cívicos" del Grupo No. 8 de la FAP y vuelos regulares de TANS) se han incrementado notablemente en los últimos 5 años.

Concluyendo, diremos que la configuración tradicional de aislamiento geográfico de la selva se ha roto definitivamente. Consecuentemente sólo aquellos grupos étnicos que huyendo se retiren a los "centros del bosque y quebradas apartadas" podrán mantener durante algún tiempo más (no mucho) su condición de aislamiento. Y en todo caso esa retirada, además de la nueva reubicación, generalmente implicará el abandono de mejores tierras por áreas menos favorables.

3.2 La "Configuración demográfica" de la selva también está siendo profundamente alterada. La "Hoya Amazónica" se ha convertido en un nuevo "melting pot" (14) donde hierven los 64 ó 67 Grupos Etnicos de origen pre-colombino junto a una población "Charapa" (15) nacida en el Departamento de Loreto, a una creciente población "Pacucho" (16) proveniente de la sierra ("serranos"), y una población "Posheco" (17) procedente del extranjera y/o de la Costa.

Las migraciones, sobre todo de la Sierra, a la selva, especialmente a la Ceja de Selva $y$ concretamente a lo largo $y$ ancho de las carreteras de penetración $y$ las márgenes de los ríos navegables (Marañón, Ucayali, Huallaga, etc.), no sólo continuará sino que aumentará en los próximos años.

Las presiones demográficas en la Cordillera Andina, y la saturación humana desempleada en los "Pueblos Jóvenes" de las ciudades Costeñas, impulsarán una mayor emigración a la Ceja de Selva y Selva. Por otra parte la Amazonía sigue siendo considerada como "Colonia interna" del país. Ello, operativizado y racionalizado en Perú, quiere decir : primero, que es la solución de los problemas que aquejan a la Metrópoli; segundo, la selva (dicen y actúan como si fuera cierto) contiene "grandes riquezas y recursos" (el eterno Dorado), tierras fértiles, etc., que hay que "colonizar, conquistar, explotar ..." "; tercero, "la selva está prácticamente vacía, es tierra de nadie, apenas si hay algunos "Chunchos" (19)-indios salvajes- que no producen nada, que hay que civilizar, convertir o integrar ... "

(14) Al caracterizar la configuración demografica como "melting pot" en modo alguno pretendemos dar a entender que la diversidad de etnias que pueblan la Amazonia, Peruana se han fusionado. e integrado. Si este concepto se ha demostrado falso aplicado a las diversas etnias que habitan y componen los Estados Unidos, mucho más inadecuada seria esa interpretación aplicada a la "Hoya" Amazonica. Pretendo sin embargo dar a entender la fricción, pluralidad, cohexistencia y agitacion de múltiples Etnias y Grupos sociales que hierven en esa "olla".

(15) Es la denominación aplicada a la población. ribereña (por habitar generalmente las riberas de los rios) y campesina (cuya actividad principal es el cultivo de chacras) que son oriundos del Dpto. de Loreto pero no proceden de Grupos Etnicos precolombinos. Charapa es una especie de tortuga muy conocida y codiciada en la $A$. mazonia, de ahi su aplicación a la población del Dpto. de Loreto en general.

(16) Es la denominación social aplicada al inmigrante "Serrano" (procedente de la Sierra). Tiene connotaciones peyorativas.

(17) Literalmente quiere decir "blanquiñoso o paliducho" y es la denominacion social ordinariamente usada para designar al grupo "gringo" en sentido generico, que denota no solo (aunque si primordialmente) a los norteamericanos, sino también a todos los extranjeros y peruanos de tez blanca, rubios.

(18) Los términos "colonizar, conquista, explotar, etc." aparecen no solo en la literatur ra periodistica, sino en documentos y discursos oficiales como expresiones ordinarias y aceptadas.

(19) Es la denominación empleada por todos los no-Nativos para designar a los Grupos Nativos de la Selva. Es un término sumamente peyorativo que exactamente quiere decir "el indio salvaje de la selva". En la zona del Ucayali (Pucallpa) suele usarse el término "Chama" que incluye principamente los Shipibo, Conibo, Campa, etc. y tiene un significado semejante (aunque menos despreciativo en general) al de "chun cho" (indio genérico salvaje-no-civilizado). 
Con esos presupuestos (falsos y peligrosos) penetran a la Selva los diferentes frentes de expansión de la Sociedad Dominante.

4. Frentes de expansión : Económico, político y cultural.

4.1 La expansión económica hacia la selva ha sido y es de cuatro frentes fundamentales: Extractivista, Pecuario, Agrícoia y Mercantil.

El "Frente Extractivista" ha sido y sigue siendo el más característico. Extracción de caucho (shiringa, borrasha), leche caspi, madera, pieles, palo rosa, castaña, oro, "pichicata", sangre de grado, etc.

En la actualidad es de suma importancia la extracción Petrolera.

La Compañía Estatal PETRO-PERU suscribió entre el 22 de Junio del 71 y el 13 de Agosto de 1973, 18 contratos para la exploración y explotación petrolera según el "Modelo Peruano" (20), dieciseis de los cuales operan en la selva y dos en el zócalo continental del Pacífico norte (Tumbes-Piura). Estos contratos envuelven a 19 Compañías Norteamericanas, dos Japonesas, dos Alemanas y una Inglesa, Francesa, Noruega y Española respectivamente.

Como puede apreciarse por el mapa de Contratos Petroleros y la amplia zona que explota directamente Petro-Perú, prácticamente toda la región de la selva y Ceja de Selva (y casi todos los Grupos Etnicos en mayor o menor grado) han sido afectados por el Frente Extractivista Petrolero.

Relacionado estrechamente con la explotación petrolera ly como expresión máxima del frente extractivista), está la construcción del Oleoducto NorPeruano de $852 \mathrm{Kms}$. desde San José de Saramuro hasta Bayovar, con un costo de \$ 697.7 millones según cifras oficiales del Instituto Nacional de Planificación. El Oleoducto se encuentra muy avanzado en su construcción. El tramo de Costa y Sierra (por Porculla) que construye el consorcio Argentino TECHINT estará terminado posiblemente en Julio de 1976; y el tramo de selva que construye el consorcio Norteamericano Williams-Sedco-Horn estará finalizado en 1976 también.

(20) Cfr. La Conferencia ofrecida el 29 de marzo de 1973 por el Grav. de Div. E. P. Marco Fernández Baca, Presidente de Petro Perú, sobre el tema "El Conirato de Operaciones Modelo Peruano". 


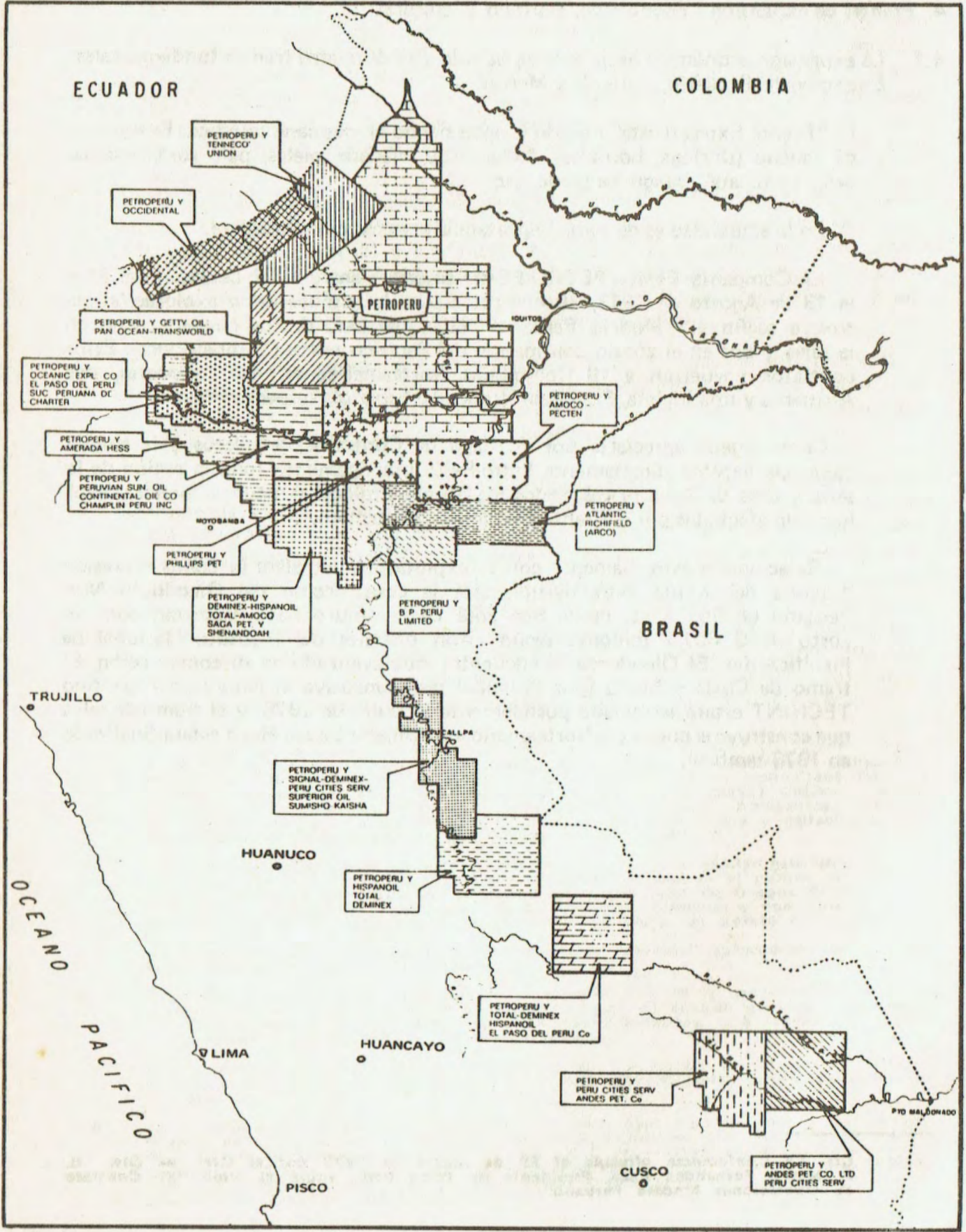




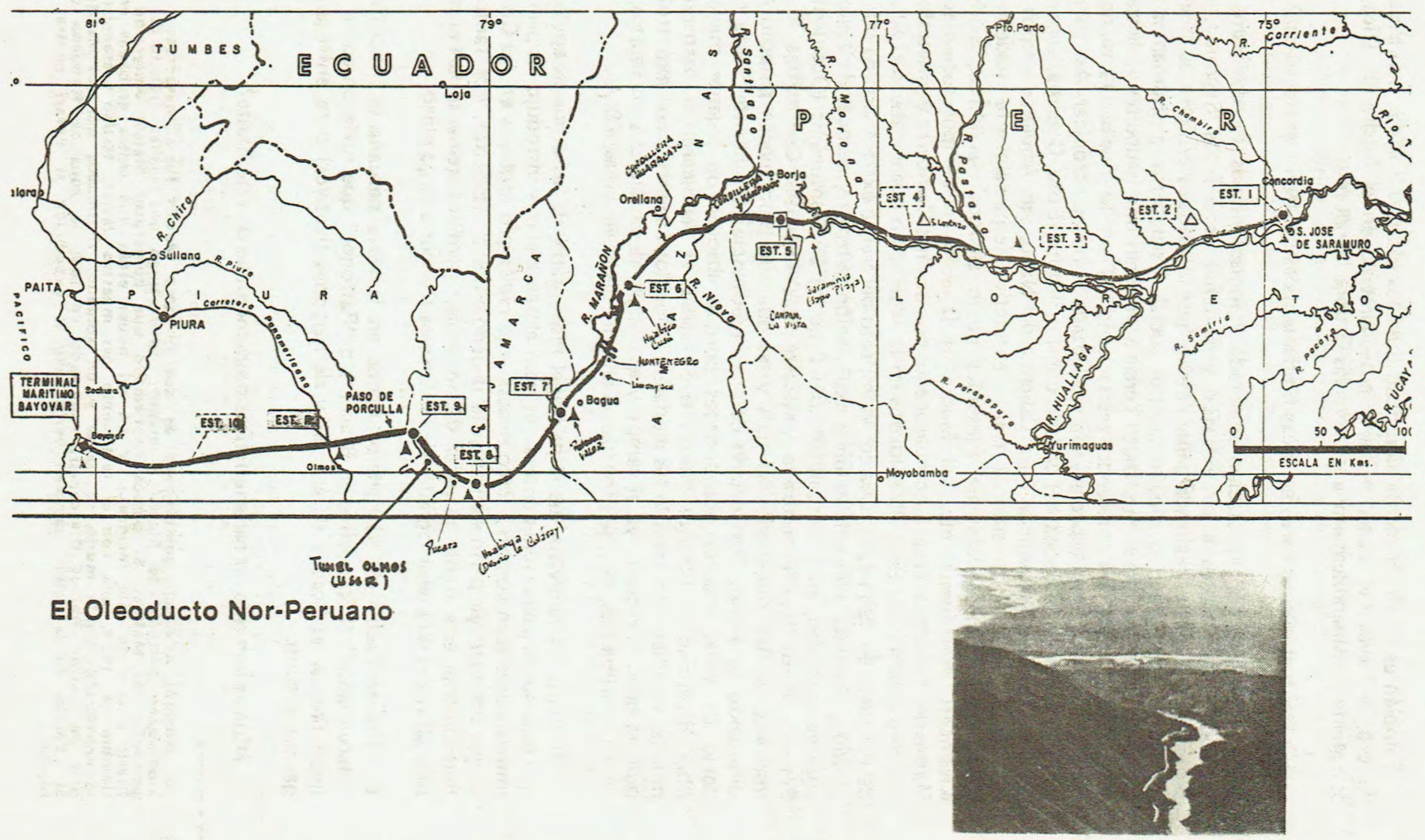


Tambiẻn es particularmente significativa en los últimos 8 años, la extracción de oro, a través del Banco Minero, especialmente en el Madre de Dios, lo que afecta considerablemente a los diversos Grupos Harak'mut.

\section{¿Cuáles han sido las características fundamentales del frente extractivista?}

Primeramente, la explotación acelerada e indiscriminada (verdaderamente, "ecocida") del recurso a ser extraído y comercializado fuera. Segundo, esta explotación suele ser realizada generalmente por individuos y/o grupos móviles, sin familia, con poco o ningún control social. Verdaderos trashumantes que dejan sin embargo cierto mestizaje. Tercero, realizan una irrupción violenta en el territorio tribal incorporando (esclavizando?) en lo posible la mano de obra Nativa altamente especializada y adaptada al bosque tropical. Así sucedió especialmente en la época del caucho con los Witoto, Bora, Coçama, Jeberino, Shipibo, Conibo, Ashaninka, Piro, Quichua del Napo, etc. Aquellos grupos que supusieron un obstáculo al frente extractivo (especialmente maderero $\mathrm{V}$ cauchero) fueron brutalmente agredidos como algunos Harak'mut, Sapiteri, Kisamberi, Wachipaeri, etc. del Madre de Dios; o en tiempos recientes los Matsés del Yakerana-Yavarí, bombardeados con aviones Camberra y ametrallados por una columna de unos 40 soldados en la expedición que encabezó el Alcalde de Requena en 1964 (21). Cuarto, el impacto del frente extractivista es intenso, rápido y disperso. La exploración y explotación petrolera, después de 3 años de enorme actividad, en la actualidad sólo 2 de las 29 Compañías (Occidental V Petro - Perú) han encontrado petróleo. Las restantes Compañías, la gran mayoría, se han marchado del país y las que aún permanecen parecen estar ultimando su salida. Han dejado como consecuencia lo siguiente : alza en el costo de vida; chacras abandonadas porque absorbieron ingente mano de obra Ribereña; se crearon nuevas necesidades; se reubicaron $\mathrm{v}$ destruyeron muchas familias; han crecido las ciudades ("Pueblos Jóvenes") con expetroleros que no quieren regresar ya al campo y que vagan desempleados en lquitos, $\mathrm{Pu}$ callpa, Yurimaguas, etc.; se propagaron enfermedades venéreas, TB ...

El frente extractivista fue el principal responsable de las primeras epidemias que diezmaron poblaciones enteras; es normalmente el que introdujo las primeras innovaciones tecnológicas, creó necesidades reales y/o espúreas en los Grupos; y que los hizo ya permanentemente dependientes del exterior. Por tanto potencialmente este frente (a pesar de no ocupar permanentemente la tierra) ha sido tal vez el más desintegrador de los Grupos Etnicos a largo plazo.

4.1.2 El "Frente Pecuario" (Ganadero) marca en la selva peruana la irrupción de "Hacendados" (Facendeiros en Brasil) y/o "Patronos". que tuvieron como finalidad limpiar el bosque de árboles y de personas (Nativos) para entregarlo al ganado vacuno.

\section{¿Cuáles han sido las características fundamentales de este frente?}

No tenemos evidencia comprobada de que un solo Matsés tuera masacrado (comunicacibon personal de Steven Romanoff, antropblogo que realiza trabajo de cam. po entre los Matsés). Si parece confirmado que numerosos Matsess emigraron a Brasil a raíz de este incidente. $\gamma$ en mi poder están dos cintas grabadas en setiembre de 1974, una con el testimonio del maestro Javier, testigo presencial de la expedicion donde murió su dadre y un soldado, victimados por los Matsés; la otra de Gaston Ramos Rivadeneira, conocido en tóda la zona de Requena como el "Tarzán de la Selva" tambien verificando la expedición al Vavarí contra los Matsés. 
Primero, su asentamiento permanente y la ocupación estable del fundo donde invirtieron dinero. Segundo, el establecimiento de relaciones patrón-peón, con las Comunidades Nativas cercanas. Tal vez ha sido ésta la dependencia más esclavizadora para numerosos nativos. La mano de obra Nativa era obtenida en numerosos casos por el "Sistema de Correrías" (22) y mantenida casi indefinidamente por el "Sistema de Habilitación" o "Enganche" (23). En la Amazonia Peruana el frente Pecuario no ha sido muy numeroso, pero su influjo ha sido permanente $y$ localizado $y$ ha producido (juntamente con el frente mercantil) el índice de mestizaje más elevado.

Los Grupos Etno-lingüísticos más afectados por este Frente han sido : los Ashaninka (especialmente en los Ríos Tambo, Perené y Alto Ucayali), los Quichuas (Yumbo, Canelo, Maca) del Río Napo, los Cocama y Cocamilla del Bajo Marañón, Huallaga, Bajo Ucayali y Amazonas, los Chayahuitas del Río Paranapura, etc.

4.1.3 El "Frente Agrícola" es el más reciente y desbastador en la Ceja de Selva $V$ en menor grado en la Selva Baja;

¿Cuáles son sus características fundamentales?. Primero, es un frente masivo de población no-Nativa que avanza a lo largo y ancho de las carretaras de penetración y ríos navegables tomando posesión (legal o lo más frecuentemente, por simple ocupación) de la tierra. Segundo, suele estar integrado por farnilias de colonos, no por individuos aislados. Tercero, suelen someter al bosque a una agricultura de monocultivo e intensiva, predominantemente para la comercialización (arroz, maíz). Cuarto, apenas se da mestizaje.

Las consecuencias son el empobrecimiento de la tierra (pobres ya desde el inicio, contra todo lo que digan aquellos que divulgan los "mitos sobre la fertilidad de la selva, paraíso agrícola"). Desbastación forestal con alteración de la ecología y extinción de flora y fauna silvestres. Invasión de tierras tribalesy conflicto sistemático y constante con la población nativa, que ante la hostigación diaria tiende a abandonar sus tierras y adentrarse en el bosque.

Los Grupos más afectados por este frente son los que indicamos al hablar de las 10 carreteras de penetración y los ubicados en los ríos navegables como los Machiguengas, Piros, Amahuacas y Yamninahuas del Bajo Urubamba; los Ashaninka del Tambo y Perené; los Conibo, Shipibo del Río Ucayali; los Cocami lla del Río Huallaga; Cocamas del Bajo Marañón, Bajo Ucayali $v$ Río Amazonas. Finalmente los Yagua y Ticuna del Bajo Amazonas.

(22) Consistía en que un Patrón no-Nativo usaba (contrataba ?) a Nativos de otra tribu o sub-grupo enemigo. Estos irrumpian violentamente en una comunidad, mataban a los hombres adultos, incendiaban el poblado y llevaban al fundo del patrón a las mujeres y niños, donde ante la imposibilidad de escapar permanecian, como verdaderos esclavos. Hasta Septiembre, de 1974 exisf́́a en ef Rio Tambo el fundo Rateri con una población Ashaninka de aproximadamente 70 familias producto del Sistema de Correrías. Esta información fue verificada por m/ en Pto. Ocopa (confluencia del río Pangoa y Perené) al entrevistar a una joven Ashanin$\mathrm{ka}$ de 24 años que apenas hacía dos ãños logró escapar del fundo, huyendo en el bote que realizaba el censo del 72. Fue conducida el fundo Rateri a los 11 años de edad.

(23) Explicaré el Sistema de Habilitación o Enganche al tratar el Frente Mercantil(Cfr. 4. 1. 4) por ser más característico (aunque no exclusivo) de ese frente de expansión, y en vinculación directa con el "Regatón". 
Conviene destacar que el frente agricola y pecuario, además de los "colonizadores" de tipo individual y espontáneo (precarios) (24), está compuesto por algunos proyectos de Colonizaciones Organizadas. Así por ejemplo la Colonia Militar de Imazita del Alto Marañón (OCECOMIL) con fines de "seguridad nacional" en el Distrito del Cenepa, en la frontera con Ecuador y en territorio Aguaruna-Huambisa. O la Colonización Genaro Herrera del Bajo Ucayali, fruto de un convenio Suizo-Peruano, que afecta a los Shipibo, Cocama y en un futuro próximo a los Matsés del Yaquerana.

4.1.4 El "Frente Mercantil" está en muchos casos ligado a las personas que forman parte de ctro frente de expansión, bien sea extractivista, pecuario, agrícolay aún político (autoridades) y cultural (misiones). Pero al frente mercantil está integrado sobre todo por comerciantes "Regatones" (25). Consiste en toda una cadena de "Intermediarios" que literalmente encadena a todos sus eslabones por medio del "Sistema de Habilitación o Enganche" y que alcanza las zonas más remotas y asiladas de la Amazonía. Los "habilitadores" (enganchadores), económicamente fuertes que residen en los centros urbanos de lquitos, y Pucallpa (con conexiones económicas fuera de la selva), "habilitan", es decir, adelantan "mercadería" o plata a otros "habilitados" (económicamente menos fuertes), quienes a su vez sub-habilitan a otros "Regatones" y asi sucesivamente hasta formar mediante intermediarios eslabonados una verdadera red mercantil en toda la selva.

¿Cuáles son las características fundamentales de este frente? Primero, la explotadora desproporción en el trueque; los Nativos, que están en el último eslabón de la cadena, tienen que vender sus productos al Regatón a precios increiblemente bajos y tienen que comprar los articulos del Regatón a precios increiblemente altos. No eran infrecuentes los casos en que los Nativos entregaban sus productos (pieles, palo rosa, caucho, madera, etc.) y/o su mano de obra, bajo la promesa del patrón-regatón de una escopeta o machete, que después de algunos años aún no recibia" . . porque todavía me debes". Segundo, la introducción de artículos totaimente innecesarios (brillantina, pan, cepillos de dientes, etc.) y la creación de necesidades espúreas. Tercero, se establece una dependencia (verdadera esclavitud) sumamente difícil de romper en el futuro. El Sistema de Habilitación o enganche cuenta con mecanismos de control sicológico (el Regatón establece numerosos lazos de "compadrazgo" y consanguinidad .... ), económico (pues proporciona artículos, también al tamentecodiciados por los Nativos, como machetes, ropa, sal, kerosene, etc.), finalmente "papel" - factura o denuncia- para los miembros de sociedades pre-literatas), etc.

El hecho es que aún hoy día resulta dificii liberarse del sistema de "enganche-habilitación" una vez encadenado por él.

(24) Conocidos en Brasil como "poseros". Son numerosos individuos (con su familia ordinariamente) que emigran a la region de selva y simpiemente ocupan, usufructuan $y$ adquieren derechos legales (Cfr. Art, 10 del DL No. 20653) convirtiéndose en propietarios de facto y/o debiendo ser indemnizados en compensacion de las "mejoras" introducidas, por las Comunidades Nativas si se encuentran en terrenos de la comunidad y los comuneros deciden su salida.

(25) Es el comerciante ambulante y flotante de la Amazonia. Recorre los rios de la selva en su bote o lancha (verdadera tienda flotante) abastecido con los articulos mas codiciados por la población tanto ribereña como nativa. Las transacciones son predominantemente de trueque (no monetarias). El Regatón es un personaje sumamente pintoresco y ambivalente (odiado y querido, pero siempre necesitado por la población que abusivamente explota). 
Concluyendo, el resultado final de la configuración económica y los diferentes frentes de expansión que caracterizan la Amazonía es el siguiente : como consecuencia de una economía predominantemente extractivista, la región sufre una descapitalización sistemática y endémica; como consecuencia de su condición geo-política de "colonia in terna", la región está siendo explotada en forma verdaderamente ecocida (26) y en función de $y$ para beneficio de las sucesivas "Coronas".

Todos los Grupos (incluyendo los Matsés) en mayor o menor grado se han hecho o están haciendo dependientes de la economía monetaria y han perdido su autosuficiencia económica, aunque algunos sub-grupos mantengan aún casi intacta su economía tradicional de trueque y subsistencia autosuficiente.

\subsection{Configuración politica :}

Ninguno de los Grupos Etno-lingüísticos que encontramos en la Amazonía Peruana alcanzó el nivel de integración política que pudiéramos llamar Estados, aun de manera incipiente (aunque la "nación Jívara", por ejemplo, contara con mecanismos de integración política a nivel intra-Tribal capaces de unir a varios miles en pie de guerra para confrontar la agresión Incaica y/o Española; sin embargo, carecía de instituciones estables para la integración política; era sólo para momentos de emergencia. Una vez superada la agresión y la crisis, el nivel de integración socio-política estable -al carecer de verdaderos Grupos Corporativos unilineales - retornaba al "Kindred" bilateral personal levemente patrilineal $y$ fundamentalmente la familia nuclear poligena).

La tendencia casi constante de todos los Grupos Amazónicos fue (por adaptación ecológica y demográfica, por conflictos internos, etc.) a dividirse en sub-grupos, en un fenómeno que podriamos denominar "citosis" socio-política.

Por el contrario las Naciones (Estados) que hoy se reparten la "olla" (nunca mejor empleada la metáfora culinaria) de la Hoya Amazónica, cuentan con mecanismos e instituciones políticas para incorporar nuevas poblaciones a la Nación Estado.

La tendencia constante de estos Estados ha sido y continúa siendo la conquista e incorporación de nuevos Grupos en un fenómeno que podríamos llamar "fagocitosis" socio-politica.

4.2.1 Los "Frentes de Expansión Politica Internacional" (Perú, Ecuador, Colombia, Brasil y Bolivia) tras conflictos abiertos $y$ latentes que aun persisten, man tienen fronteras internacionales que dividen numerosos Grupos Etnicos. Así por ejemplo, los Huambisa (Shuar-Jivaro), los Aguaruna, los Achual, los Candoshi, Ios Quicha del Napo (Yumbo, Canelo, Maca), los Secoya-Angotere, los Secoyas-Piojé, quedan separados por la frontera con Ecuador, La misma situación encontramos entre los Witoto-Muruí separados por la frontera Colombiana. Más triste es el caso de los Ticuna divididos y separados por Colombia, Brasil y Perú. También encontramos a los Matsés posiblemente los

(26) Aunque la Ley Forestal del año 1975 muestra una seria preocupación por la preservación ecológica, sin embargo resulta muy difícil y costosa su implementación. eficaz en la práctica. 
Capishto (Grillos), los Culina, Sharanahua, Chaninahua, Mastanahua, PiroManchineri y posiblemente los Yaminahua, Amahuaca, divididos entre Brasil y Perú. Finalmente el Grupo Esa'exa, separado por la frontera Peruano-Boliviana.

4.2.2 Los Frentes de expansión política Nacional en la Amazonía son Ios siguientes:

1. En toda la región, pero de modo especial en las cuatro zonas fronterizas, (ya que cualquier otra autoridad está sometida a ella) existen Guarniciones Militares. $Y$ en mucho menor grado la Guardia Republicana.

2. También en zonas fronterizas, pero no sólo allí, la PIP (Policía de Investigaciones del Perú).

3. La Guardia Civil ejerce el control social inmediato en todos los conflictos entre nativos y entre estos y la población no-nativa. Es por tanto la de mayor impacto en los Grupos Etnicos y los casos de discriminación (por racismo y/o falta de comunicación) son muy frecuentes.

4. En la mayor parte (posiblemente en todos) de los Distritos se han nombrado y ejercen sus funciones, autoridades civiles (Teniente Gobernador, Alcalde, Juez de $\mathrm{Paz}$ ) ninguno de los cuales proviene de los Grupos Etnolingüísticos.

5. De suma importancia, para un número creciente de Grupos Etnicos, es toda una serie de Funcionarios Gubernamentales:

- SINAMOS (Sistema Nacional de Apoyo a la Movilización Social) organismo creado por el Gobierno Revolucionario en 1971 para "concientizar" y organizar las "basea populares" (Cooperativas, Pueblos Jóvenes, Ligas Agrarias, Comunidades Campesinas, etc. y Comunidades Nativas), que ha tendido a confundir la gran palabra revolucionaria de "participación" por la gran realidad de "manipulación". Ha sido y (aunque recortado en sus funciones, presupuesto, personal, etc. en 1975) sigue siendo el organismo político de mayor impacto para las Comunidades Nativas. La Dirección General desde Lima, algunas OZAMS (oficinas zonales) y algunas ORAMS (oficinas regionales) desde la promulgación de la Ley de Comunidades $\mathrm{Na}$ tivas del 24 de Junio de 1974, han trabajado eficientemente para el reconocimiento y registro de Comunid: les entre los Grupos Ashaninka, Gran Pajonalino, Nomatsiguenga, Piro, ye as comunidades Amahuaca, Yaminahua, Machiguenga y Aguaruna. Y especialmente las Comunidades Conibo, Shipibo y Cashibo.

- Otros Funcionarios Gubernamentales del frente de Expansión política lo constituyen ingenieros, topógrafos, etc. del Ministerio de Agricultura a través de las Zonas Agrarias encargadas de la Reforma Agraria. El impacto mayor de éstos se ha dado en la Ceja de Selva. También conviene mencionar a los funcionarios del Ministerio de Salud, aunque su contacto e influjo entre los Nativos ha sido mucho menor. El Hospital Amazónico ( $Y$ arina-Pucallpa) sin embargo, si ha tenido un impacto fuerte entre los Conigo y Shipibo, pues aparte del hospital la Fundación Amazónica lleva un proyecto de desarrollo ganadero pai upos Nativos. 
6. Finalmente, aunque de reciente creación e influjo en la selva, pero creo de enorme potencial, conviene señalar la creación de la Federación Agraria Departamental "Selva Socialista" en Octubre 1975, que marca la presencia de la CNA (Confederación Nacional Agraria) (27) y el FDRP (Frente de Defensa de la Revolución Peruana) que se presenta como "la"organización de los Nativos. Posteriormente en este trabajo recogeré este punto para alertar sobre un peligro que considero serio para la autodeterminación de las Etnias Indigenas.

¿Cuáles han sido y son las características fundamentales del frente de expansión política? Primeramente, la interferencia en el control social de las sociedades tribales; no obstante esa interferencia en la mavoría de los casos es parcial hasta tal punto que no permite funcionar los sistemas tradicionales, ni los suplanta eficientemente por el nuevo control; y en la casi totalidad de los casos, esa interferencia o es errónea (por desconocer totalmente la cultura $\mathrm{Na}$ tiva) o es injusta (por falta de comunicación real, por el etnocentrismo opor prejuicio racista). Segundo, un nuevo sistema de autoridades políticas con objetivos ajenos (si no contrarios) al Grupo Etnico, es adoptado alterando los sistemas tradicionales de autoridad y escalas de prestigio. Aún aquellas comunidades en las que SINAMOS ha nombrado o promovido autoridades nativas, los mecanismos tradicionales de autoridad y escalas de prestigio. Aún aquellas comunidades en las que SINAMOS ha nombrado o promovido autoridades nativas, los mecanismos tradicionales no pueden ya funcionar adecuadamente. Tercero, los Grupos Etnicos, han perdido definitivamente el derecho a la autodeterminación y carecen de instituciones adecuadas aún para hacer escuchar su voz, mucho menos para influir y nada para decidir sobre su destino e intereses.

\subsection{Configuración Cultural :}

De una manera análoga al contraste que observamos a nivel político entre la Sociedad Internacional y Nacional (Estados expansivo y "fagocitarios") vs. las Sociedades Tribales (Grupos antocontenidos y con tendencia a la "citosis"), observamos igual contraste a nivel cultural. En la Sociedad Nacional y Occidental observamos expansión e imposición ideológica, mientras que en las Sociedades Tribales constatamos aislamiento sin tendencia a la expansión ideológica $\mathrm{y} / \mathrm{o}$ dominación cultural.

El "Frente de expansión cultural" en la Amazonía está compuesto (sin negar que los frentes económico y político también forman parte del frente cultural) específicamente por la expansión religioso-misional y la educativa.

4.3.1 Iglesia Católica : En la Región Amazónica cuenta con 9 jurisdicciones eclesiásticas (territorios administrativos) (Cfr. Mapa adjunto) con 117 puestos misionales y un total de 857 misioneros o "agentes de pastoral" (sacerdotes, religiosos, religosas y laicos o seglares) (28).

(27) Con anterioridad a la Federación Departamental "Selva Socialista", Ia CNA se hace presente en la región de la selva a través de la Liga Agraria de Satioo que incluyo al Ashaninka Quinchoquer como Vice-presidente, y también de reciente formación la Federación Departamental de San Martín.

(28) Los datos aquí presentados fueron recolectados personalmeate en el campo durante 1974 de abril a diciembre. Aunque en ulteriores visitas a la selva he podido constatar pequeños cambios de personal y puestos misionales, la situación descrita, es básicamente idéntica y válida en la actualidad. 
JURISDICCIONES ECLESIASTICAS

DE LA IGLESIA CATOLICA EN LA

AMAZONIA PERUANA

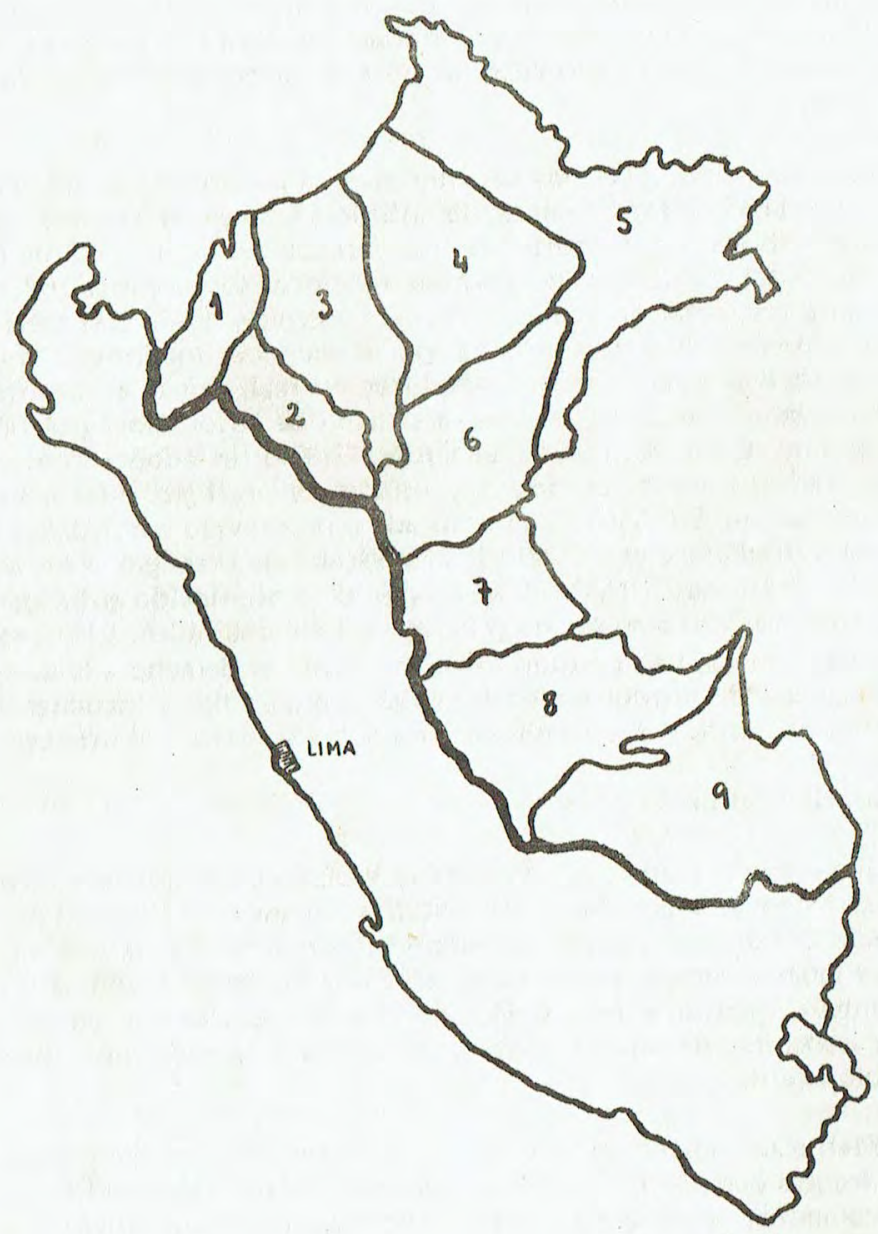

Nombre de Jurisdicción

Sede Central

Extensión Geog.

1. Vicariato S. Francisco Javier del Marañón

2. Prelatura de Moyobamba

3. Vicariato de Vurimaguas

4. Vicariato de Iquitos

5. Vicariato S. José de Amazonas

6. Vicariato de Requena

7. Vicariato de Pucallpa

8. Vicariato de S. Ramón

9. Vicariato Puerto Maldonado
- Jaén (Cajamarca)

- Moyobamba (S.Ma.)

- Vurimaguas

- Iquitos

- Indiana

- Requena

- Pucallpa

- San Ramón

- Pto. Maldonado
$40,000 \mathrm{~km} 2$ aprox.

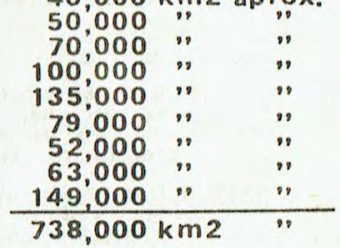

26 
CUADRO GENERAL DE LOS 8 VICARIATOS Y LA PRELATURA DE MOYOBAMBA

\begin{tabular}{|c|c|c|c|c|c|c|c|}
\hline \multirow[t]{2}{*}{ Jurisdic. Eclesiástica } & \multirow{2}{*}{$\begin{array}{l}\text { Grupos Tribales residentes } \\
\text { en esa Jurisdicción }\end{array}$} & \multirow{2}{*}{$\begin{array}{l}\text { Total } \\
\text { puestos } \\
\text { misional }\end{array}$} & \multicolumn{4}{|c|}{ Agentes de Pastoral } & \multirow{2}{*}{$\begin{array}{l}\text { Total } \\
\text { Mlisio- } \\
\text { aneros. }\end{array}$} \\
\hline & & & $\begin{array}{l}\text { Sacer } \\
\text { dotes }\end{array}$ & $\begin{array}{l}\text { Reli- } \\
\text { giosos }\end{array}$ & $\begin{array}{l}\text { Reli- } \\
\text { giosas }\end{array}$ & & \\
\hline $\begin{array}{l}\text { 1.- Vic. S. Javier } \\
\text { Marañón }\end{array}$ & Aguaruna y Huambisa & 17 & 25 & 11 & 83 & 0 & 119 \\
\hline $\begin{array}{l}\text { 2. Prelatura Moyo- } \\
\text { bamba. }\end{array}$ & Lamisto y Aguaruna & 12 & 24 & 4 & 39 & 1 & 68 \\
\hline $\begin{array}{l}\text { 3.- Vicariato Yuri. } \\
\text { maguas }\end{array}$ & $\begin{array}{l}\text { Cocama, Cocamilla, Cha- } \\
\text { yahuita, Aguaruna, Huam- } \\
\text { bisa, Murato, Achual, Sha- } \\
\text { pra, Balsapuertino, Jeberi- } \\
\text { no, Andoa. }\end{array}$ & 7 & 11 & 2 & 36 & 0 & 49 \\
\hline 4.- Vicariato Iquitos & $\begin{array}{l}\text { Shimacu, Jivaro, Inga del } \\
\text { Tigre, Iquito, Cocama. }\end{array}$ & 13 & 29 & 6 & 56 & 0 & 91 \\
\hline $\begin{array}{l}\text { 5. Vic. S. José Ama- } \\
\text { zonas }\end{array}$ & $\begin{array}{l}\text { Quichua (Yumbo, Maca, } \\
\text { Canelo) W-Muruí, W-Mui- } \\
\text { nane, S-Angotere, S-Piojé } \\
\text { Bora, Yagua, Ocaina, Koto, } \\
\text { Arabela, Matsés,Ticuna, Co } \\
\text { cama, Capishto, Remo? , } \\
\text { Pisagua }\end{array}$ & 14 & 18 & 9 & 51 & 21 & 99 \\
\hline $\begin{array}{l}\text { 6. Vicariato Reque- } \\
\text { na }\end{array}$ & $\begin{array}{l}\text { Shipibo, Conibo, Cocama, } \\
\text { Iskobákebu, Capanahua }\end{array}$ & 7 & 15 & 3 & 24 & 0 & 42 \\
\hline 7.- Vicariato Pucallpa & $\begin{array}{l}\text { Shipibo, Conibo, Cashibo, } \\
\text { Cacataibo, Ashaninka, Co- } \\
\text { cama }\end{array}$ & 13 & 19 & 5 & 51 & 0 & 75 \\
\hline 8.- Vicariato S. Ramón & $\begin{array}{l}\text { Amuesha, Ashaninka, No- } \\
\text { matsiguenga, G. Pajonal, } \\
\text { Piro }\end{array}$ & 18 & 24 & 4 & 84 & 4 & 116 \\
\hline $\begin{array}{l}\text { 9. Vic. Pto. Maldona- } \\
\text { do. }\end{array}$ & $\begin{array}{l}\text { Piro, Ashaninka, Machi- } \\
\text { guenga, Amarakaeri, Wachi- } \\
\text { paeri, Amahuaca, Yamina- } \\
\text { hua, Cashinahua, Sharana- } \\
\text { hua, Mastanahua, Culina, A. } \\
\text { rasaeri, Kisambaeri, Toyoe- } \\
\text { ri, Iñapari, Manchineri, Esa' } \\
\text { exa }\end{array}$ & 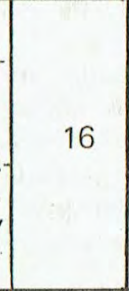 & 53 & 17 & 67 & 61 & 198 \\
\hline & TOTAL: & 117 & 218 & 61 & 491 & 87 & 857 \\
\hline
\end{tabular}


Sin embargo conviene matizar el valor de esos datos reales con vista al tema que nos ocupa, que es el frente de expansión cultural (religioso-misionero) vis-avis las Comunidades Nativas. Tendré por tanto que especificar cuáles son los puestos misionales y quiénes (cuántos) los misioneros católicos que "de facto"trabajan con los Grupos Nativos. El cuadro general antes presentado se refería a todos los puestos misionales y a todo el personal que trabaja tanto con la población nativa como no-nativa, en la Selva y Ceja de Selva.

1.- Vicariato de San Francisco Javier del Marañón:

- Puesto Chiriaco: ubicado en la margen derecha del Río Chiriaco cerca de su confluencia con el Río Marañón. Cuenta con tres sacerdotes, dos religiosos $\mathrm{y}$ ocho religiosas. Total 13 misioneros.

- Puesto Santa María de Nieva: ubicado en la confluencia del Río Nieva con el Río Marañón. Cuenta con un sacerdote, dos religiosos y cinco religiosas. Total 8 misioneros.

- Puesto Huampaní ubicado en la margen derecha del Río Cenepa, próximo a la Guarnición Chávez Valdivia. Cuenta con un sacerdote y dos religiosas. Total 3 misioneros.

- Puesto Ipacuma: ubicado en la margen derecha del Alto Río Nieva. Cuenta con tres religiosas.

- Puesto Chinganasa: ubicado en la margen derecha del Rio Santiago hacia la mitad de su curso en territorio peruano. Cuenta con tres religiosas.

2. Prelatura de Moyobamba:

En esta jurisdiccion, aunque hay dos Grupos Nativcs, Lamisto y Aguaruna, y dos puestos cercanos uno en Lamas con dos sacerdotes y tres religiosas, y otro en Rioja con un sacerdote y cuatro religiosas, su trabajo con los nativos es prácticamente nulo.

3.- Vịcariato de Yurimaguas:

- Puesto Santa María: ubicado en la margen derecha del Alto Río Cahuapanas, afluente del Marañón. Cuenta con dos religiosas. Afecta a Chayahuitas y Aguarunas.

- Puesto Apaga: En el Río Apaga, afluente del Marañón; cuenta con dos religiosas y afecta a los Aguarunas.

- Puesto Jeberos: ubicado en la ciudad de Jeberos; cuenta con cuatro religiosas y afecta a los Jeberinos, grupo étnico ya desintegrado.

- Puesto de Lagunas: ubicado en la ciudad de Lagunas en el Río. Huallaga, pero la labor con los Cocamilla, grupo también bastante desintegrado, es mínima.

- Equipo Médico volante: recorre los Ríos Pastaza lafecta un poco a los: Achual y Candoshi-Shapra), Río Morona (afecta un poco a los Huambi- 
sa) y Río Cahuapana con su afluente Río Sillay (afecta a los Chayahuitas). El equipo incluye una religiosa enfermera.

4.- Vicariato de Iquitos:

De los trece puestos misionales, diez están en la misma ciudad de lquitos; los tres restantes: Nauta (en la confluencia Marañón-Ucayali), Santa Catalina (margen izquierda del Bajo Marañón) e Intuto (margen derecha Río Tigre) son puestos para "ribereños" no-nativos.

5.- Vicariato de San José de Amazonas:

- Puesto de Monterrico: ubicado en la margen izquierda del Río Napo en la parte alta de su curso en Perú. Allí residen y se desplazan por el río, un sacerdote y. tres religiosas. Afecta a los grupos Quichua-Yumbo, Quichua-Canelo, Quichua-Maca, Secoya-Angotere, Arabela, Witoto-Muinane y Vacacocha. Esporádicamente a los Bora, Yagua, Koto, Matsés.

6.- Vicariato de Requena:

Todos los puestos misionales están orientados hacia la población mo-nativa.

7.- Vicariato de Pucallpa:

De los trece puestos misionales, seis están en la ciudad misma de Pucallpa ; cinco están orientados a caseríos y/o pueblos no-nativos.

- Puesto San Antonio: ubicado en la margen derecha del Río Ucayali, cerca de Pucallpa. Cuenta con un sacerdote $\mathrm{V}$ tres religiosas, aunque visitan alguna Comunidad Shipibo, su trabajo es casi exclusivamente con ribereños.

- Puesto Curiaca: ubicado en el Río Caco, afluente por la derecha del Alto Ucayali. Cuenta con un sacerdote $\mathrm{y}$ tres religiosos $\mathrm{y}$ afecta realmente a los Conibo.

8.- Vicariato de San Ramón:

- Puesto Quillazú: ubicado cerca de Oxapampa. Cuenta con un sacerdote y cuatro religiosas afectando al grupo Amuesha de Miraflores.

- Puesto Puerto Ocopa: ubicado en la confluencia del Río Pangoa con el Perené. Cuenta con un sacerdote, un religioso y cuatro religiosas. Afecta a los Ashaninka.

- Puesto Cheni: ubicado en el río Tambo. Cuenta con un religioso y una misionera seglar. Afecta a los Ashaninka.

- Puesto San Miguel de Otica: ubicado también en el Río Tambo; cuenta con una misionera seglar y afecta a los Ashaninka.

- Puesto de Cutivireni, ubicado en la margen derecha del Río Ene; cuenta con un sacerdote, un religioso $\mathrm{y}$ una misionera seglar. 
9.- Vicariato de Puerto Maldonado:

- Puesto Shintuya: ubicado en la margen derecha del Río Alto Madre de Dios. Cuenta con un sacerdote, un religioso y tres misioneras seglares. Afecta a los Amarakaeri, Wachipaeri, Piro (de Diamante).

- Puesto Sepahua: ubicado en la confluencia del Río Sepahua con el Río Urubamba. Cuenta con tres sacerdotes, un religioso, siete religiosas y tres misioneras seglares. Afecta a los Piro, Amahuaca, Yaminahua.

- Puesto Kirigueti: ubicado en la margen izquierda del Río Urubamba en su confluencia con el Río Picha. Cuenta con un sacerdote, un religioso, $y$ tres misioneras seglares. Afecta a los Machiguenga.

- Puesto Timpía: ubicado en la margen derecha del Río Urubamba en su confluencia con el Timpía. Residen un sacerdote y dos misioneras seglares y afecta a los Machiguenga.

- Puesto Koribeni: ubicado en el Alto Río Urubamba, donde residen un sacerdote $\mathrm{y}$ seis religiosas. Afecta al grupo Machiguenga.

- Puesto Chirumbia: ubicado en el río Chirumbia, afluente por la derecha del Alto Río Urubamba. Cuenta con la presencia de dos misioneras seglares. También afecta a los Machiguenga.

- Puesto El Pilar: ubicado en la margen izquierda del Río Madre de Dios, cerca de Puerto Maldonado, donde trabajan un sacerdote $y$ dos misioneras seglares. Afecta a los Amarakaeri principalmente.

- Equipo móvil del Purús: que recorre el Río Purús aunque reside ordinariamente en Sepahua y se desplaza al Purús durante tres meses al año. Cuenta con un sacerdote $y$ tres religiosas. Afecta a los grupos Cashinahua, Sharanahua, Mastanahua, Yaminahua y Culina. 


\section{CUADRO RESUMEN DE PUESTOS MISIONALES Y MISIONEROS CATOLICOS}

que realmente trabajan con y/o afectan a los Grupos Etnicos.

\begin{tabular}{|c|c|c|c|c|}
\hline \multicolumn{2}{|c|}{ Jurisdicción Eclesiástica } & \multirow{2}{*}{$\begin{array}{l}\text { Total } \\
\text { Puestos } \\
\text { Mision. } \\
5\end{array}$} & \multirow{2}{*}{$\begin{array}{c}\begin{array}{c}\text { Total } \\
\text { Misio- } \\
\text { neros }\end{array} \\
30\end{array}$} & \multirow{2}{*}{$\begin{array}{l}\text { Total Grupos } \\
\text { Tribales afec- } \\
\text { tados. } \\
2\end{array}$} \\
\hline 1.- & Vic. San Fco. Javier del Marañón & & & \\
\hline 2.- & Prelatura de Moyobamba & 0 & 0 & 0 \\
\hline 3.- & Vicariato de Yurimaguas & $2 *$ & 5 & 2 \\
\hline 4.- & Vicariato de Iquitos & 0 & 0 & 0 \\
\hline 5.- & Vicariato de S. José de Amazonas & 1 & 4 & 7 \\
\hline 6.- & Vicariato de Requena & 0 & 0 & 0 \\
\hline 7.- & Vicariato de Pucallpa & 1 & 4 & 1 \\
\hline 8.- & Vicariato de San Ramón & 5 & 17 & 2 \\
\hline 9.- & Vicariato de Puerto Maldonado & $8 *$ & 39 & 10 \\
\hline & & 22 & 99 & 24 \\
\hline
\end{tabular}

Nota: * (indica que además de los puestos misionales existe un Equipo Móvil que se desplaza sistemáticamente).

Concluyendo: El Frente real de expansión misionero-católico que afecta a los Grupos Etno-lingüísticos directamente, está constituído por 22 puestos misionales de los 117 que operan en la selva y ceja de selva; y por 99 misioneros solamente de los 857 que trabajan actualmente en la Amazonía, que afecta, en mayor o menor grado, a 23 Grupos Etnicos de los 64 (posiblemente 67) que habitan la selva y ceja de selva peruana.

\subsubsection{Swiss Indian Mission (S.I.M.):}

Desde el 1 de agosto de 1967 cambió su denominación legal a “Misión Suiza en el Perú (M.S.P.)" y parece incluir ahora diversas Iglesias Evangélicas Europeas, predominantemente y/o exclusivamente Suizas y Alemanas (29)

En 1958 iniciaron en la selva el Instituto Bíblico, ubicado en el Km. 15 de la carretera Pucallpa. Desde la fundación del Instituto han pasado

(29) Para una información más amplia, ver el informe de Manuel Garcia . Rendueles: "Evangelización en el Dpto. de Loreto" (no publicado) 1975. 
por los cursos del Instituto Bíblico 400 Nativos provenientes de 25 Grupos Etnicos que ulteriormente retornaron a sus Comunidades como "Pastorcitos". según denominación que le aplican en la zona de la selva.

Desde 1957, cuando comenzó sus operaciones, han desfilado aproximadamente 80 misioneros extranjeros del SIM en el Perú. En la actualidad cuenta con unos 35 misioneros (incluyendo sus familiares).

El 29 de octubre de 1974 el SIM firmó un convenio con el Ministerio de Educación - Dirección Zonal 63 de Pucallpa (firma el Director Zonal Mario H. Pereyra Almeida y Enrique Fritschi Brandenberger por la Misión Suiza), para participar en la operación ALFIN.

Los Grupos Etnicos más afectados por este frente de expansión religioso-misionero-protestante (de tendencia fundamentalista) son: los Aguaruna, Huambisa, Achual, Ashaninka, Shipibo; Conibo, Machiguenga, Piro y. Yagua principalmente.

Aunque son instituciones independientes, trabajan en estrecha colaboración con el Instituto Lingüístico de Verano capitalizando sobre la infraestructura (traducciones Bíblicas, escuelas bilingües, medios de transportes, etc.) del ILV.

4.3.3. South American Indian Mission (S.A.M.): Inició sus actividades en el Perú en diciembre de 1929 estableciéndose en lquitos. Pero desde 1962 trasladó su sede central a la zona de Pucallpa también.

Desde 1957 el S.A.M. mantiene un "Seminario de Estudios Bíblicos" con 29 alumnos en Tipishca, ubicado cerca de Contamana pero en la margen izquierda del Río Ucayali. Cuentan con una base en CashiboCocha (detrás de las instalaciones del S.I.M.) con aeropuerto y tres avionetas propiedad del S.A.M.

El S.A.M. es una Asociación de Iglesias Evangélicas; la financiación, y el personal (aproximadamente 60 entre pastores, técnicos, colaboradores, etc.) provienen de EE. UU.

Los Grupos Etno-lingüísticos más afectados por este frente de expansión son los Ashaninka del Río Pichis, concretamente la comunidadde Puerto David, San Juan, Puerto Ocopa, Puerto Amistad, Lagarto, Graza Plaza y Mosquito Playa. También entre los Ashaninka de la Comunidad de Chicosa en el Alto Ucayali y en Mazamari del Departamento de Junín, donde el S.A.M. dispone de una radio emisora.

También desarrolla el S.A.M. una intensa actividad entre los Shipibo y Conibo en las Comunidades de Canán, Paococha, Nueva Betania, Junín Pablo, Caimito Awaipa, Belén, Utukuro, San Francisco y otas del Ucayali.

4.3.4. Adventistas del Séptimo Día: Cuenta en Perú con cuatro centros: en Lima, Chiclayo, Arequipa e lquitos. Este último que es el que nos ocupa, se fundó en 1930 en la ciudad de Iquitos, pero también como o- 
tras denominaciones protestantes, en Mayo de 1975 trasladó su.-sede a Pucallpa. Este frente se autodenomina "Misión del Oriente" y maneja recursos aéreos (avionetas) y unaas 30 pistas de aterrizaje en diversas Comunidades o Caseríos de la selva manteniendo su base aérea en Yarinacocha.

Cuenta con dos familias norteamericanas misioneras ordenadas en $U$ $S A$, unos quince misioneros nacionales y aproximadamente 400 laicos ("personas bautizadas que recibieron estudios bíblicos y se dedican a predicar La Palabra") de los cuales aproximadamente 80 son Nativos.

Todos los aspectos sociales-asistenciales de la Misión son realizados por medio de OFASA (Obra Filantrópica y de Asistencia Social Adventista).

Los Grupos Etnicos más afectados por este frente de expansión son: los Chayahuita, especificamente en las Comunidades de Panán (base principal en esa zona), y las de Zábalo Yacu, Sinar, Betel, Armenia, y Lomalinda. También han concentrado sua actividad con los Shipibo en las Comunidades de Paucocha o Pauyán, Amaquiría (Shipibo-Conibo) y San Francisco. La Comunidad Ashaninka y "mestizos" de Puerto Putaya, la Comunidad Shaguaya (Ashaninka y Shipibo), Alto Aruza (Ashaninka).Par ticularmente influyente es el centro de operaciones de la Comunidad de Unini (Ashaninka y Piro) que dispone de escuela particular, clínica de material noble y emisora de radio propiedad de la Misión Oriente. Una situación análoga encontramos en la Comunidad de Nevati (entre Ashaninka). Finalmente existen otras Comunidades Ashaninka tales como las de Jordán, Sta. Isidora, Sta. Isabel, San Pedro, San Juan, Aguachin i, Betania, Paúti, (en el Gran Pajonal) donde la Misión del' Oriente ejerce particular influjo.

4.3.5. Instituto Lingüistico de Verano (SIL: Summer Institute of Linguistics):

Este frente de expansión cultural es el más complejo y diversificado tanto por la diferenciación de instituciones integrantes (University of $\mathrm{O}$ klahoma, Wycliffe Bible Translators y JAARS, entre otras), como por su vinculación ("técnicosasesores") con el Sistema de Educación Bilingüe, como por la estrategia del método de trabajo entre los Grupos Etnicos (30).

El SIL inició sus actividades en el Perú en 1945. En 1953 con la creación del Sistema de Educación Bilingüe asumió la coordinación de las Escuelas Bilingües entre los Nativos de la Selva; en la actualidad legalmente todas las actividades administrativas son llevadas directamente por funcionarios nacionales del Ministerio de Educación, permaneciendo el SIL en calidad de asesoría técnica.

(30) Resuita bastante esclarecedor un "documento interno" del propio ILV titulado Estrategia para la conlusion de nuestro trabajo en el Peru" 1971. Alli se especifi can: 1. Sugestiones para dentro de la Tribu, II. Sugestiones para fuera de la Tribu. Seguidamente se especifican las finalidades del Instituto Linguistico: "Para el desarrollo de la Comunidad y Crecimiento Espiritual: nuestra finalidad principal es ayudar al Indio a depender de Dios y capacitarle para resolver los principales de sus problemas con independencia del ILV y sus colaboradores, pero recibiendo ayuda $y$ orientacion del Gobierno y de organizaciones privadas y otras personas" (Cfr. p. 2). Seguidamente el documento especifica los fines generales, medios para conseguirlos y objetivos minimos en cada tribu en los capitulos siguientes: Educacion / II. Medicina, III. Desarrollo Economico / IV. Social Legal, V. Uso de las Sagradas Escrituras. / VI. Organización y Liderazgo Eclesiástico. El do: cumento interno termina: “... Tan pronto como sea posible nosotros necesitamos salir de la escena de manera que bastantes de ios programas 'SECULARES' puedan continuar sin nuestra intervencion." 
El informe 1971 - 1974 publicado por el SIL, en el Anexo 2, pág. 95, especifica la relación de "Lingūistas" del Instituto y Grupos Idiomáticos con quienes trabaja en Perú. El total allí asciende a 75 miembros; pero el total de miembros de esta compleja organización se estima en 205 sin incluir el personal nacional (31).

EI SIL trabaja con 32 Grupos Idiomáticos (38 Grupos Etnicos) enla Amazonía, siendo los más influidos: los Aguaruna (con 5 miembros del SIL) los (Campa) Ashaninka (con 4), los Huambisa (con 5), los Chayahuita (con 4), los Candoshi-Shapra (con 4), los Capanahua (con 3) ; con dos miembros del SIL encontramos a los Grupos: Achual-Jívaro, Amahuaca, Arabela, Bora, Nomatsiguenga, Gran Pajonalino, Cashinahua, Culina, Witoto-Murui, Machiguenga, Matsés (Mayoruna), Koto (Orejón), Quichua del Pastaza, Sharanahua-Marinahua, Shipibo-Conibo, Ticuna, Urarina y Yagua. Finalmente con un solo miembro del SIL encontramos los siguientes Grupos: Amarakaeri, Amuesha, Cashibo, Ocaina, Piro, Taushiro.

En conclusión, podemos afirmar que el frente de expansión cultural (religioso, educativo, científico), por ese orden, del ILV, es sin lugar a duda el de mayor impacto para las poblaciones Nativas de la selva. Sin embargo hasta el momento carecemos de un análisis $v$ evaluación serios (sin demagogias $y / 0$ sin propagandas) sobre esta compleja institución.

4.3.6. El Ministerio de Educación: No podemos aquí elaborar y documentar en detalle el tema, pero si dejar constancia que uno de los principa les frentes de expansión cultural en la selva es el Ministerio de Educación que ha hecho un significativo esfuerzo en los últimos 20 años.

El Ministerio de Educación en la selva, se apoyó predominantemente en las misiones (católicas v/o protestantes) para la educación especialmente de los Nativos en la Amazonía. Sin embargo, en los últimos 5 años, $\vee$ de manera creciente es el propio Ministerio a través de sus funcionarios en las diferentes Regiones $y$ Zonas educativas quien constituye fundamentalmente este frente cultural.

Para concluir esta parte de expansión cultural (religioso-educativo) desearía indicar algunas de sus consecuencias.

1. En primer lugar, los Nativos se han reubicado y concentrado demográficamente (bien sea por "propia iniciativa", bien por mecanismos de manipulación) alrededor de personas y/o centros del frente de expansión cultural. El Ministerio de Educación requiere 40 alumnos para poder tener escuela; ello conlleva generalmente una concentración mínima de 150 personas alrededor de la escuela. Los Puestos Misionales Católicos generalmente suelen agrupar (a veces por sistema de internado) los Nativos. EI ILV, el SAM y otros, suelen reubicar y concentrar la población Nativa alrededor de las pistas de aterrizaje para sus aviones. EI SIM con sus "casas de culto" y el sistema de "pastores" también propiciada por la Ley de Comunidades Nativas, han fomentado la reubicación $y$ concentración. 
2. En segundo lugar y como consecuencia de lo anterior, se alteran los patrones de asentamiento y residencia; se ha alterado la vivienda multifamiliar ("maloca", "cocamera") por la casa unifamiliar, afectando también los sistemas de cooperación aprovisionamiento y redistribución de los grupos.

3. Tercero, también relacionado con los dos puntos anteriores, se ha afectado la dieta al no poder realizar convenientemente el sistema ro tativo de tala-quema, al agotarse la flora y fauna en la zoria de con centración demográfica, sin haberse implementado adecuadamente otros recursos alimenticios. Consecuencia de ello son la desnutrición y la anemia.

4. Se percibe un aumento en las fricciones sociales intra-comunales, al haberse aglutinado indiscriminadamente miembros de diferentes grupos corporativos (clanes, linajes, etc.) e incluso de diferentes (aun rivales) grupos Etnicos.

5. Son introducidos, de manera a-funcional en la mayoría de los casos, nuevos sistemas de creencias y valores ajenos (y opuestos) a los que funcionalmente mantiene el Grupo. Es un gran número (si no en todos) de Nativos la alfabetización, conversión, aculturación (proveniente de fuera $y$ dirigida hacia afuera del Grupo) suele producir la migración de Nativos fuera del grupo (ciudades, Ejército, mano de obra, etc.) y/o la desadaptación socio-cultural si permanece el Grupo.

6. Se introducen escisiones, dicotomías, divisiones dentro de los Grupos -Y aún dentro de las Comunidades. "Yo soy del ILV. . . yo soy de la Misión. . yo soy Evangélico..." etc. Por adhesiones ("conversiones") a sectas, grupos, instituciones, funcionarios del SINAMOS, o la Liga Departamental, etc. - muchas veces compradas por servicios y ayudas discriminatorias- se rompe en numerosos casos (por no decir en todos) la unidad étnica.

Conclusión: Ha tratado de presentar los frentes de expansión provenientes de la Sociedad Dominante, los diversos intermediarios (segmentos sociales) económicos, políticos y culturales que confrontan los Grupos Etno-lingüísticos de la Amazonía. ¿Cuál ha sido el resultado de esa confrontación de sociedades evolutiva mente desfasadas, bióticamente separadas, y socio-culturalmente no sólo diferentes sino contrarias?

1. Algunos grupos se han exinguido en lo que llevamos del siglo (32).

2. Otros fueron drásticamente reducidos, como la nación de los Witoto, Koto, Bora, Secoya, Arabela, Amarakaeri (y demás grupos Harakmbut), Omaga, Amuesha, etc. etc.

(32) Referimos nuevamente a Coriat, Op. Cita. especificamente a la pág. 11. Aunque su clasificación de "Tribus conocidas" presenta cierta confusión en la denominacion de cada grupo, resulta aleccionador contrastar su lista con el anexo y mapa de 64 (67?) grupos que presentamos en este trabajo. En ese contrasteconstatamos que varios grupos han desaparecido. 
3. Otros Grupos (hablamos de grupos étnicos no de individuos) -que ciertos et nocéntricos consideran "integrados", "Civilizados"- se han convertido en infra-proletariado amazónico, incorporándose a una sociedad altamente estratificada para ocupar el último peldaño de la escalera social, destribalizados, culturalmente estancados, castrados y simplemente explotados. Asi por ejemplo los Cocama, Cocamilla; sub-grupos Ashaninka del Tambo-Perené, Amuesha Miraflorino, Iquito. Quichua Santarrosino, Iñapari, Chayahuita, Ticuna, etc.

4. Otros Grupos (prácticamente todos) ante las presiones bióticas, demográficas, ecológicas, económicas, politicas y socio-culturales acarreadas por los frentes expansivos han experimentado: a)-Profunda alteración en el tipo de asentamiento, subsistencia, parentesco, control social, etc. b)-Desplazamiento y reubicación generalmente a zonas menos favorables. c)-Debilitamiento alarmante es la propagación de TB, enfermedades venéreas y la anemia.

\section{PARTE}

Situación especifica de cada Grupo Etnolingüistico

Carecemos en la actualidad de estudios sistemáticos y comparativos para poder documentar definitivamente los puntos que trataré de presentar esquemáticamente a continuación. Sin embargo, estimo conveniente compilar en un solo tra bajo - consciente de lo tentativo de algunos datos- el material disponible. Una presentación global podrá servir de marco de referencia que indudablemente dedeberá ser profundizado y revisado con estudios ulteriores (33).

Trataré de ubicar y evaluar todos los Grupos Etnolingüisticos de la Amazo. nía Peruana bajo las siguientes categorias o columnas:

Columna 1.- Ubicación del Grupo Etnolingüistico en la yeografía Amazónica.

Columna 2.- El tipo de ocupación territorial del Grupo en cuestión. Distinguiré entre el Tipo "C" (i. e. Compacto) que indica una ocupación te. rritorial contigua, sin infiltración significativa de no-nativos dentro del territorio tribal. Clasificaré como Tipo "A" (i. e. Atomizado) cuando el territorio tribal está disgregado $\vee$ notablemente infiltrado por población no-nativa. Finalmente clasificaré como Tipo "I" (i. e. Intermedio) cuando la situación es intermedia entre C $\vee$ A

Columna 3- Indicaré la población estimada del Grupo Etnolingüistico.

Columna 4. Trataré de evaluar la tendenciáa de la curva demográfica del grupo. El signo $(+)$ indicará que la población tiende a crecer; el signo (-) indicará que la población está decreciendo; $y$ el signo (=) que la población se mantien estable.

(33) El Centro Amazónico de Antropología ha iniciado un estudio sistematico, (etno. grafico y cros-cultural) de todos los grupos tribales de la Amazonia Peruana. Es. te y otros estudios revisaran y corregiran datos de nuestro informe y vendran a llenar el enorme vacio etnologico y aun etnografico que existe en la litaratura antropologica de la selva peruana. 
Columna 5. En esta categoría trataré de evaluar el grado de identidad étnica del grupo. El signo " $F$ " (i. e. Fuerte) indicará que la identidad étnica del grupo es vigorosa. El signo " $D$ " (i. e. Débil) indicará la desintegración étnica. $Y$ finalmente el signo " $\mid$ " (i. e. Intermedia) indicará una situación intermedia entre " $F$ " y " $D$ ".

Esta evaluación de la identidad étnica estará basada en cinco criterios:
a)- Endogamia vs. exogamia del grupo.
b) - Tipo de actividad económica predominante (tradic. vs. mo- der.).
c)- Lengua usada por la comunidad parlante (nativa vs. caste- Ilana).
d)- Uso del vestido (tradicional vs. moderno).
e)- Autoafirmación y autopresentación de los miembros del gru- po (nativo específico vs. "civilizado", peruano, etc.).

Columna 6.- En esta categoría trataré de evaluar la tendencia que se percibe en el grado de identidad étnica: tiende a aumentar, fortalecerse $(+)$, o tiende a debilitarse $(-)$; finalmente si se mantiene estable $(=)$.

Columna 7.- Aqui trataré de indicar el uso de la lengua. ¿Cuál es la lengua exclusiva o predominante usada por el Grupo Etnolingüístico? El signo " $\mathrm{N}$ " (Nativo) indicará que la comunidad parlante usa exclusivamente la lengua nativa. El Signo "N/C" indica que ambas lenguas (nativa $\mathrm{y}$ castellana) son usadas pero con predominio claro de la nativa. El signo " $\mathrm{N}=\mathrm{C}$ " indica que el uso de ambas lenguas es aproximadamente igual sin predominio claro de ninguna. EI signo " $\mathrm{C} / \mathrm{N}$ " implica uso de ambas lenguas pero con predominio claro del castellano. $Y$ finalmente el signo " $\mathrm{C}$ " indicará que exclusivamente usan la lengua castellana.

Columna 8.- Esta categoría clasificará el tipo o el grado de contacto del Grupo con la Sociedad Nacional. Distinguiré si el grupo se encuentra en situación de " $A$ " (i. e. Aislamiento) sin contacto significativo, y/o directo; $y$ especificaré si el aislamiento actual es pre-contacto, es decir que nunca tuvieron un contacto significativo durante las tres últimas generaciones con la sociedad occidental (nacional); o si el aislamiento actual es post-contacto, es decir que sí tuvieron contacto en las tres últimas generaciones, pero que rehuyeron y se retiraron. El signo "E" (i. e. Esporádico) indica un contacto no intenso $\mathrm{y} / \mathrm{o}$ no permanente sino intermitente $\mathrm{y}$ ocasional. El signo " $P$ " (i. e. Permanente) indicará que el grupo se encuentra en una situación de contacto permanente, especificaré si es del tipo1 (con claro efecto desintegrador del grupo.) o del tipo 2 (sin claro efecto desintegrador del grupo).

Columna 9.- Esta categoría tratará de evaluar el tipo de vivienda que predomina en el Grupo, usando como criterios dos elementos: primero la constitución familiar de la casa; y segundo la arquitectura empleada. Así, el signo "T" (i. e. Tradicional) indicará que el tipo de vivienda" es claramente tradicional. EI signo " $\mathrm{M}$ " (i. e. Moderna; 
implicará que la vivienda (en su constitución familiar y/o en su construcción) es claramente aculturada no-tradicional. Finalmente el signo " $l$ " (i. e. Intermedia) indicará una situación media entre " $T$ " $\mathrm{v}$ "M".

Columna 10.- Aquí evaluaré la calidad de la vivienda $\vee$ será clasificada como "B" (Buena) "M" (Mala) o " $\mathrm{M}$ " (Intermedia) teniendo como criterio: primero la limpieza e higiene; segundo el espacio y la amplitud; tercero la funcionalidad y calidad de los materiales empleados en la construcción y el ajuar; finalmente, el esmero y aćbado puesto en la vivienda.

Columna 11.- En esta categoría pretendo evaluar las facilidades educativas (aspecto cuantitativo solamente) que el grupo encuentra disponibles $\mathrm{y} / \mathrm{o}$ accesibles. El signo " $A$ " (i. e. Abundante) indicará que más de un 60 o/o de la población escolar del grupo tiene fácil acceso (menos de una hora de viaje por trocha o canoa) a escuelas. El signo " $E$ " (i. e. Escasa) indica que menos del 40 o/o de la población escolar tiene fácil acceso. El signo "I" (i. e. Intermedio) indica una situación media entre " $A$ " $y$ " $E$ ". Finalmente el signo "O" (i. e. Cero) implica que el grupo no dispone de ninguna escuela fácilmente accesible.

Columna 12.- Aquí sin embargo trataré de evaluar la calidad educativa. Clasificaré como "C" (i. e. Castellanizante) cuando más de un 60 o/o de las escuelas accesibles al grupo, exhiban maestros y/o material escolar no-nativo. Clasificaré como "N" (i. e. Nativa) en caso contrario. Y como " $I$ " (i. e. Intermedia) cuando la situación de la calidad educativa sea media entre las categorías " $\mathrm{C}$ " y " $\mathrm{N}$ ". Finalmente clasificaré como " $\mathrm{O}$ " (i. e. Cero) cuando no exista ninguna escuela fácilmente accesible a la población escolar del grupo.

Columna 13.- La categoría trece busca evaluar cuál es la situación del grupo en lo que se refiere a la atención sanitaria, es decir las facilidades médicas fácilmente accesibles (34) (menos de dos horas de viaje usando medios de transporte ordinarios $\mathrm{v}$ al alcance de la mano de los nativos) al grupo.

Clasificaré como "B" (i. e. Buena) cuando más del 50 o/o del grupo tiene fácil acceso a Hospital y Posta Sanitaria y Dispensario y Botiquines administrados por Promotores de Salud nativos (35). Clasificaré de "l" (i. e. Intermedia) cuando al menos Dis-

(34) El término accesible lo entendemos en un sentido estrictamente geográfico tanto en lo referente a las escuelas como en lo referente a facilidades en la atención sanitaria que trato en la Columna $x i$ y XIII (Página 53). Con ello no pretendo ignorar el hecho de que un elevado tanto por ciento de esas facilidades educativas y/o sanitarias aunque geográficamente son accesibles, sin embargo culturalmente no, -omo es. el caso de la Posta Médica de Imazita en el Alto Marañón $y$ otros muchos ejemplos que podrian citarse. Aqui prescindimos de ese aspecto (accesibilidad o inaccesibilidad cultural) y entendemos el iermino estrictamente en sentido geográfico; o distancia medible y cuantificable.

(35) El término "Hospital" implica la presencia de más de un medico y facilidades pa $\mathrm{ra}$ intervenciones quirúrgicas de gravedad. "Posta Médica" implica la presencia de
un médico. "Dispensario"requiere solamente la presencia de enfermera o enfermeras registradas. "Promotor de Salud" es el término aplicado a ciertos Nativos (aunque en aigunos casos puede no serlo) que han recibido algunas instrucciones sanitarias y tratan solamente casos leves y ordinarios. 
pensarios y Promotores de Salud sean fácilmente accesibles a más del 50 o/o de la población. Clasificaré como " $M$ " (i. e. Mala) cuando solamente tienen acceso a Promotores de Salud, y por tanto no a Hospital, ni Posta Médica, ni siquiera Dispensario. Finalmente clasificaré como "O" (i.e. Cero) cuando el grupo carece de las facilidades anteriormente mencionadas.

Columna 14.- Esta última categoría simplemente tratará de establecer la situación del grupo con respecto a la posesión legal de tierras. Clasificaré con un "Si" aquellos casos en que todo el grupo Nativo o más del 90 o/ de las comunidades (según ley de Com. Nativas No. 20653) han sido legalmente inscritas en los Registros del Estado. Se clasificará como "No" en todos los demás casos.

Por razones de espacio y también para poder tener una visión global y sintética de todos los 63 (posiblemente 67) grupos etnolingü is tiços, trataré el tema de la siguiente forma: primeramente, recorreré, cada grupo (por orden alfabético) indicando solamente las categorías o columnas I (i. e. su ubicación geográfica) y II (i. e. la población estimada y/o censadal por requerir mayor espacio $y$ para no comolicar excesivamente el cuadro sintético-general que clasificará también cada grupo en las restantes categorías o columnas (Cfr. Anexo).

\section{1.- ACrual :}

Habita las regiones del Río Morona, Alto Pastaza y especialmente la zona del Río Huasaga, todos ellos afluentes del Marañón y por la margen izquierda. El territorio tribal de los Achual hacia el norte penetra en Ecuador.

La población se estima en 3,000 aproximadamente en territorio Peruano (36).

\section{2.- AGUARUNA (Awajum, Aents.) :}

Ocupa la región del Alto Río Marañón, con sus afluentes Chiriyacu, Shimutaz, Cenepa-Comaina-Numpatkem, Río Nieva, Bajo Santiago, Apaga, Yurapaga y Potro. También habitan la vertiente del Río Mayo, hacia Rioja, afluente del Río Huallaga, y algunos se extienden hacia el norte penetrando en el Ecuador.

La población estimada de los Aguaruna en territorio Peruano se calcula en unos 25,000 .

3.- AMAHUACA :

Este grupo habita los ríos Inuya, Mapuya y Sepahua, afluentes del Río Bajo Urubamba por la derecha. También se extienden por el Río Curanja, afluente del Río Purús, hacia la frontera con Brasil.

Su población se calcula en 2,000 aproximadamente.

(36) Las Categorias restantes aparecen en el Anexo 1 en el cuadro general siniético de
todos los grupos. 
Ocupa la zona del Río Colorado, afluente por la derecha del Río Madre de Dios. También residen algunos en la Misión Dominicana, puesto de Shintuya (Alto Madre de Dios) y el Pilar en la margen izquierda próxima a Pto. Maldonado. Se encuentran algunos Amarakaeri también en los ríos Pu-Kiri y Wasorokwe.

La población se estima en unos 800 aproximadamente.

5.- AMUESHA :

Se extienden por las regiones de los Ríos Palcazu y Pozuzo que forman el Río Pachitea, afluente del Ucayali por la margenizquierda. También en la zona de Chuchuras, Yurinoki, Cacazú, Miraflores (Quillazú).

La población estimada es de 5,000.

6.- ANDOA (Shimigae) :

Ocupan la región del Alto Río Pastaza y zona intermedia hacia el Río Macusari, afluentes ambos del Río Marañón por la izquierda. Penetran también en la zona Ecuatoriana.

Su población se estima en unos 60 .

\section{7.- ARABELA :}

Habitan la quebrada de Arabela, afluente del Río Curaray, y a su vez afluente por la derecha del Río Napo.

Su población se estima en unos 180.

\section{8.- ARASAERI y PUKIRIERI :}

Los Arasaeri habitan básicamente en Villa Santiago ubicada en el Km. 160 de la carretera Quince Mil a Pto. Maldonado. El grupo Pukirieri se encuentra en Sta. Rosa ubicada en el Km. 141 de la carretara Quince Mil a Pto. Maldonado; también se extienden por el Río Malinowski, Quebrada Dos de Mayo y Río Pukiri afluentes por la derecha del Madre de Dios.

La población estimada es de aproximadamente 40. Arasaeri y unos 50 Pukirieri.

\section{9.- BALSAPUERTINO :}

Habitan en la zona de Balsapuerto, Varadero y Alto Rio Parana pura, afluente del Río Huallaga por la margen derecha.

Su población se calcula en unos 3,000. 


\section{0.- BORA :}

Se extienden por el Estirón de Cusco en el Río Ampiyacu, afluente del Amazonas por la margen izquierda, y habitan las comunidades de Brillo Nuevo, Puerto Colonia, Puca Urquillo en el Río Yaguasyacu, finalmente ocupan áreas comprendidas entre los ríos Ampiyacu y Putumayo. mente.

La población Bora se calcula en 800 comuneros aproximada-

\section{1.- CACATAIBO :}

Parece tratarse de un sub grupo Cashibo, que habita básicamente en el Río San Alejandro, en Sinchi Roca.

Población estimada en unos 250.

\section{2.- CANDOSHI-MURATO :}

Habitan en la región del Río Nucuray, afluente del Amazonas, por la margen izquierda. También hacia los ríos Ungumayo, Alto $\mathrm{Pa}$ vayacu y Pastaza, afluentes del Marañón por la margen izquierda.

Su población es de 1,500 aproximadamente.

\section{3.- CANDOSHII-SHAPRA :}

Se extienden por la región del Bajo Pastaza y Huasaga, zona del lago Rimachi.

Población estimada en 2,500.

\section{4.- ASHANINKA (Campa) :}

Se extienden por los Ríos Perené, Ene y Apurímac; por los ríos Pongoa y Tambo (que al unirse con el Río Urubamba forma el Ucayali) Los Ashaninka se extienden también por el Bajo Urubam. ba, Alto Ucayali $Y$ afluentes de éste como el Sheshea, Yurúa, Pachitea $y$ Pichis.

La población se calcula en 20,000 aproximadamente.

\section{5.- GRAN PAJONALINO (Campa) :}

Habita fundamentalmente en la región del Gran Pajonal y Río Unini, alfuente del Alto Ucayali por la izquierda.

Su población se estima en unos 8,000. 
16.- NOMATSIGUENGA (Campa) :

Habita la zona del Ríoo Anapati, Masamari, Alto Pangoa, Sonomoro, Sanibeni, Kinteri, etc.

Población estimada en unos 6,000 .

\section{7.- CAPANAHUA :}

Ocupan las zonas de los Ríos Buncuya y Tapiche, ambos afluentes del Río Ucayali por la derecha.

Población estimada en unos 800 .

18.- CAPISHTO (Grillo) :

La información sobre este grupo, aunque su existencia parece confirmada, (37) es estremadamente escasa y tentativa. Parece ocupar la zona entre el Bajo Río Yavari, afluente del Amazonas por la derecha, y el Rio Sta. Rosa hacia el oeste.

Población no estimada.

\section{9.- CASHIBO :}

Habita en la zona del Aguaitía, Sambuyacu y Sunguruyacu. También se extienden al este hacia la zona del Pachitea.

Población estimada en 2,000 aproximadamente.

\section{0.- CASHINAHUA ("Honikoin") :}

Se extiende a lo largo del Río Curanja, afluente del Río Purús por la margen izquierda, y la zona comprendida entre esos dos ríos. En su mayor parte residen en Brasil.

La población Cashinahua en Perú se estima entre 600 y 900.

21.- COCAMA:

Ocupa las márgenes de los grandes ríos, Bajo Marañón, Bajo Ucayali y Amazonas. También se ha asentado en los "pueblos Jóvenes" de las ciudades Amazónicas como Pucallpa, Requena, Iquitos, etc.

Es particularmente difícil, tanto por la dispersión como sobre todo por la desintegración étnica, hace un estimado de la población de este grupo. Se calcula sin embargo en unos 20,000. 


\section{2.- COCAMILLA :}

Habita las márgenes del Bajo Río Huallaga $y$ especialmente el "Barrio Cocamilla" de la ciudad de Lagunas, en la margen derecha. del Río Huallaga.

Su población (con las salvedades hechas al hablar de los Cocama) se estima en unos 8,000 .

\section{3.- CONIBO :}

Se extienden por el Alto Río Ucayali hasta la Zona de Pucallpa inclusive. Especialmente zona de Curiaca, por el Río Caco margen derecha del Ucayali.

Población estimada en unos 6,000.

\section{4.- CULINA :}

Ocupa la parte baja del Río Purús, aguas abajo de la desembocadura del Curanja, y la región del Sta. Rosa en la frontera con Brasil. Se extienden también dentro del territorio Brasileño.

La población estimada en territorio Peruano es de 800 aproximadamente.

\section{5.- CHAMICURO (?) :}

Aunque vo no he obtenido confirmación directa, aún de la mera existencia de este grupo, aparece sin embargo en alguna comunicación oficial (38) y se les ubica en la zona de Pampa Hermosa, en un afluente del Río Huallaga próximo a la ciudad de Lagunas.

La población se estima en unos 160 por dicha comunicación.

\section{6.- CHANINAHUA :}

Habitan en la zona del Río Purús. Y su población se estimaen unos 200 aproximadamente.

\section{7.- CHAYAHUITA :}

Ocupan las zonas de los Ríos Cahuapana y Sillay, afluentes del Río Marañón por la derecha. También habitan la zona del Shanisi y del Alto Río Paranapura, afluente del Huallaga por la izquierda.

Población estimada en unos 5,000. 
28.- ESA'EXA (Huarayo) :

Se extienden por la zona del Bajo Madre de Dios y su afluente por la margen derecha, el Río Tambopata, adentrándose también y sobre todo en territorio boliviano. Hay grupos de Esa' Exa en la misión del Pilar, en Villa Santiago y en Palmareal.

La población estimada en territorio peruano es de 900 aproximadamente.

\section{9.- HUAMBISA o SHUAR :}

Habitan la zona del Alto y Medio Río Santiago $y$ al este hacia el Río Morona inclusive, ambos afluentes del Río Marañón por la izquierda. El grupo Huambisa se extiende al norte en territorio ecuatoriano, donde se les conoce como Shuar, Jivaro. madamente.

La población estimada en territorio Peruano es de 5,000 aproxi 30.- INAPARI :

Este grupo se halla prácticamente desintegrado, casi extinguido, sin territorio tribal propio. Algunos miembros habitan marginalizados en Puerto Maldonado y zona de Lagarto.

Población no estimada.

\section{1.- IQUITO :}

Fundamentalmente habita la zona del Alto Río Nanay, afluente del Amazonas por la izquierda y los miembros más destribalizados residen en los Pueblos Jóvenes de Iquitos ciudad.

La población se estima en unos 250 aproximadamente.

\section{2.- ISKOBAKEBU (Isconahua) :}

Reside en el curso inferior del Río Callaría, afluente por la derecha del Río Ucayali, cerca, aguas arriba, de la desembocadura del Río Pisqui.

Población no estimada.

\section{3.- JEBERINO :}

Ocupa principalmente la zona de Jebero, cabeceras del río Aypena con sus afluentes Yarakyacu, Yanayaku y Pampayacu, todos ellos desembocando en el Bajo Río Huallaga por la izquierda.

Como en el caso de los Cocama y Cocamilla, dada la desintegración étnica del grupo, es difícil hacer un estimado pero su población puede ser tentativamente calculada en 3,500 miembros. 
Se encuentra en la zona del Alto Río Tigre y afluentes Corrientes y Macusari, desembocando todos ellos en el Río Marañón por la margen izquierda.

Un grupo Jivaro de unas 10 familias ha sido trasladado $y$ es mantenido por la Agencia Turistica "Amazon Lodge \& Safarir" an la margen derecha del Río Amazonas, a 90 minutos (en deslizador) de la ciudad de Iquitos aguas abajo.

Su población se estima en unos 800 .

\section{5.- KISAMBAERI :}

Habitan en vuelta Grande del Rio Madre de Dios, compartiendo el territorio con el Grupo Toyoeri; también residen en el Rio Pukiri, mezclados con el Grupo Sapiteri.

La población se estima en unos 25 aproximadamente.

36.- koTo (Orejón) :

Su territorio se extendía tradicionalmente por los Ríos Yanayaku y Sucusari, afluentes por la margen izquierda del Bajo Río $\mathrm{Na}$ po. Tembién las cabeceras del Río Algodón, afluente por la derecha del Río Putumayo y finalmente la zona del Río Ampiyacu, afluente por la izquierda del Bajo Amazonas.

La población se estima en unos 600 aproximadamente.

\section{7.- MACHIGUENGA :}

Habitan en zona muy extensa. Toda la región del Río Urubamba, desde Koribeni (cerca de Quillabamba) hasta cerca del Río Sepahua; inclusive los Ríos Mishagua, Camisea, Timpia, Ticumpinía, Yave ro, Chirumbia por la margen derecha del Urubamba; $\vee$ los ríos Picha y Kirigueti por la izquierda. Se extiende por el Alto Río Manú (incluyendo el Parque Nacional de Manú). Finalmente en el Dpto. Madre de Dios, encontramos Machiguengas en Huacaría, San Salvador, Misión Shintuya y Misión El Pilar y también en San José de Kerene.

Población estimada en unos 12,000.

Asentados en el Bajo Río Curanja y el Purús.

Su población se estima en 50 comuneros aproximadamente.

39.- MARUBO (? ) :

La información que tenemos de este grupo es sumamente im- 
precisa $\mathrm{V}$ personalmente no he podido ni siquiera verificar la existencia misma del grupo. Parece ser que ocupan la zona del Río Tamshiyacu al este del Río Blanco, afluentes del Bajo Ucayali por la derecha; compartirían la misma zona con el Grupo Remo, cuya existencia es aún más dudosa.

Población no estimada.

40.- MASTANAHUA. (o Mastinahua) :

Habita con otros Grupos "Nahuas" la cuenca del Purús fundamentalmente.

Población estimada en unos 300 aproximadamente.

41.- MATSES (Mayoruna) :

Ocupan la zona del Rio Yakerana con sus afluentes, la zona este del Río Blanco hacia el Río Yavarí, afluente del Bajo Amazonas. Los Matsés se extienden al este del Yavarí en territorio Brasileño.

La población estimada en territorio Peruano es de 1,000 aproximadamente.

42.- MAYO-PISAGUA (?) :

Este Grupo, al igual que los Chamicuro, Marubo y los Remq es también altamente desconocido. Aunque aparece en la literatura actual, yo no he podido constatar ni siquiera su existencia.

Población no estimada.

43.- OCAINA - ANDOQUE :

Habita en la zona del Río Ampiyaku, en Estirón de Cusco; el Río Yaguasyaku, en puerto Isango; y también el Rio Putumayo, en Estrecho de India.

La población estimada es de 200 Ocaina $v$ unos 50 Andoque.

44.- OMAGUA :

Grupo altamente distribalizado fundamentalmente ubicado en San Joaquín de Omagua, en la margen izquierda del Río Marañón.

Población estimada en unos 600.

45.- PIRO Y PIRO - MANCHINERI (o Maniteneri) :

El grupo Piro propiamente, habita en el Río Bajo Urubamba $y$ su afluente por la derecha el Río Sepahua. También se extiende por el Alto Ucayali y sus afluentes los Ríos Pachitea y Cushabatay. Fi- 
nalmente encontramos Piros en Diamante $v$ Misión Shintuya en el Río Alto Madre de Dios. $Y$ por ser un dato peculiar de los Piro, conviene mencionar que varios han formado familia con otros Grupos (particularmente Ashaninka, Machiguenga $\vee$ Amahuaca) habiéndose desplazado de su zona a la de esos grupos.

El grupo Piro-Manchineri (o Maniteneri) ocupa una comunidad en el Río Yaku y sobre todo se extiende hacia Brasil. Pero la información de este sub-grupo es también muy escasa.

La población Piro en territorio Peruano se estima en unos 3,500.

\section{6.- QUECHUA - ALAMA :}

Habita en la zona del Bajo Río Tigre, afluente del Marañón por la margen izquierda.

Población estimada en 1,200 aproximadamente.

\section{7.- QUECHUA - INGA :}

Ocupa la zona del Bajo Rio Pastaza y afluentes.

La población estimada por la Dirección General de Organizaciones Rurales es de 3,000. Creo sin embargo que la cifra es un tanto inflada.

48.- QUECHUA - LAMISTO :

Habita varias comunidades del Departamento de San Martín, particularmente Lamas: Distritos de Sisa, Pongo; Chazuta, Pamashto, etc.

Población estimada en 22,000 aproximadamente.

49.- QUICHUA - CANELO,

50.- QUICHUA - MACA,

51.- QUICHUA - YUMBO :

Estos tres sub-grupos Quichuas, hąbitan el Río Napo en zona Pe ruana $y$ se extienden al norte por territorio Ecuatoriano. de 12,000 .

La población estimada en territorio peruano es aproximadamente,

\section{2.- QUICHUA-SANTARROSINO:}

Transportados desde el Río Napo en tiempos del caucho, habitan los Fundos Alerta y Santa Rosa en la zona de los Rios Muymanu y Manuripe, en el Departamento de Madre de Dios.

La población estimada es de 50 aproximadamente. 


\section{3.- SAPITERI (o Sinireri) :}

Ocupan el Departamento de Madre de Dios, zonas del Río Pukiri, la boca del Waorokwe, Puerto Alegre, Vuelta Grande, Villa Santiago y Río Sabaluyoc (Kosñipata y Cusco).

Población estimada en unos 50 miembros.

\section{4.- SECOYA - ANGOTERE :}

Habitan la Quebrada de Santa María, afluente por la izquierda del Río Napo, alfuente a su vez del Amazonas por la izquierda. También se extienden por la Quebrada de Angusilla, afluente por la derecha del Río Putumayo que se une al Amazonas por la izquierda.

(Nota: Tanto los Secoya-Angotere como los Secoya-Piojé, parecen estar emigrando a territorio Ecuatoriano por influjo del "Pastor José", ecuatoriano Secoya trasportado por avión del ILV del Ecuador a Angusilla para convencerlos $y$ migrar)

La población estimada en Perú es de 300 miembros.

\section{5.- SECOYA - PIOJE :}

Se extiende por el Río Alto Putumayo, especificamente en la Quebrada de Yubineto y el Río Campuya. Los Secoya-Piojé se extienden también al norte en territorio ecuatoriano $y$ colombiano al este.

La población se estima en unos 400 aproximadamente.

\section{6.- SHARANAHUA :}

Habita en la región del Alto Río Purús hasta la desembocadura del Río Curanja y también las cabeceras del Río Chandless.

Población estimada en unos 300 aproximadamente.

\section{7.- SHIPIBO :}

Se extienden por toda la zona intermedia del Río Ucayali Y sus afluentes a ambas márgenes, desde el Río Sheshea, Pachitea, Tamayo, Aguaytía y Pisqui hasta el Cushabatay inclusive.

Población estimada en unos 9,000 aproximadamente.

\section{8.- TICUNA :}

Habitan la parte del Bajo Amazonas Peruano hasta la frontera con Brasil y Colombia. La parte baja de los Rios Yavarí y Putumayo, con una concentración especial en Cushillo-Cocha. Los Ticuna se extienden ampliamente en territorio colombiano $\vee$ brasileño. 
madamente.

La población estimada en territorio peruano es de 5,000aproxi-

\section{9.- TOYOERI}

Habitan dentro del Departamento de Madre de Dios, las comunidades de Vuelta Grande, Lagarto y la Misión El Pilar en el Río Madre de Dios. Algunos miembros mezclados con Piros habitan en la comunidad de Diamante en el Alto Madre de Dios.

\section{Población estimada en unos 80 aproximadamente.}

\section{0.- URARINA (Shimacu o Cimarrón) :}

Ocupan la región del Río Chambira (con sub afluentes, Tigrillo, Pucullacu y Aricol, afluente por la izquierda del Marañón. También las cabeceras del Urituyacu. Algunos residen en la región del Río Simbillo afluente por la derecha del Río Corrientes, a su vezafluente por la izquierda del Marañón.

Población estimada en unos 1,500 miembros.

\section{1.- WACHIPAERI :}

Habitan la comunidad de San Salvador en el Río K'eros y la de Huacaría en el Río Tono, ambos afluentes del Madre de Dios por la derecha. Encontramos también Wachipaeris en Pilcopata, Misión Franciscana, y en Shintuya, Misión Dominicana. Alguno reside mezclado con Piro, en la comunidad de Diamante próxima a la confluencia del Río Manú con el Alto Madre de Dios.

Población estimada en unos 500.

62.- WITOTO - MUINANE :

Viven en las cabeceras de los Ríos Ampiyacu y Yahuasyaku, afluentes del Amazonas por la izquierda. Habitan la comunidad de Estrecho en el Río Putumayo. Los Witoto-Muinane se extienden ampliamente hacia el este, en territorio Colombiano.

Población estimada en unos 500 en territorio peruano.

\section{3.- WITOTO - MURUI:}

Ocupan especialmente el Río Ampiyaku y las cominidades de Fortaleza, Negro Urco, Sara Isla en el Rio Napo. Algunos residen en las comunidades de Estrecho y Remanso en el Río Putumayo y finalmente en los Ríos Campuya y Yaguas.

Su población en territorio peruano es estimada en unos 600 . 


\section{4.- YAGUA :}

Se extienden por el Bajo Amazonas, Quebradas Caballo-Cocha, Rios Asambaza, Orosa y Motahuayo; Río Bajo Napo, Río Apayacu, Quebrada Vainilla; Rio Cajocuma, Corotú, (Pacuyacu); Ríos Atacuari Y Boyahuasu; Río Loreto-Yacu, Nanay y Mazán.

Población estimada en unos 3,200 miembros.

\section{5.- YAMINAHUA :}

Grupo muy disperso se extiende por la región de los Ríos Mapuya, Yurúa y Bajo Urubamba. También se extienden hacia los Ríos Piedras, Curanja y Purús en la vertiente hacia Brasil.

Población estimada en unos 2,000.

66.- ZAPARO (Taushiro, Aushiri, Vacacocha) :

Carecemos de datos para hacer una descripción precisa de su $\mathrm{u}$ bicación y/o un estimado cualificado sobre la población.

\section{7.- REMO (?) :}

Aunque fuentes actuales afirman la existencia del grupo, personalmente no he podido verificar en el campo la existencia del grupo Remo, habiendo estado en la región atribuida a este grupo.

\section{CONTENIDO DE I.AS COLUMNAS ETNOGRAFICAS}

"Survey cross-cultural de los Grupos

Etnolingüísticos de la Amazonía Peruana"

I Ubicación geográfica.

II Ocupación territorial: Compacta. Atomizada. Intermedia.

III Composición demográfica, población del Grupo.

IV Tendencia de la curva demográfica: crecimiento, decrecimiento, estabilizada.

$\checkmark$ Grado de Identidad Etnica: Fuerte. Débil. Intermedia.

Nota: Evaluada en términos de:
a)- Endogamia.
b)- Tipo de Actividad económica.
c)- Uso del vestido.
d)- Uso de la lengua.
e)- Autoafirmación del Grupo.

VI Tendencia que muestra el Grado de Identidad Etnica.

VII Uso de la Lengua : $N=$ Sólo Nativà.
NC = Predominio de Nativa, pero también usan cas- tellano.
$\mathrm{N}=\mathrm{C}$. Ambas lenguas por igual.




$$
\begin{aligned}
& \text { CN }=\begin{array}{l}
\text { Predominio del Castellano, pero también usan } \\
\text { la Nativa. }
\end{array} \\
& C=\text { Sólo Castellana. }
\end{aligned}
$$

VIII Grado de Contacto con la Sociedad Nacional:
a). Aislamiento: - Precontacto.
- Postcontacto.
b). Esporádico.
c). Permanente: - Con claro efecto desintegrador.
- Sin claro efecto desintegrador.

IX Tipo de Vivienda (según la constitución familiar y según la arquitectura):
a)- Tradicional.
b)- Moderna.
c)- Intermedia.

X. Calidad de Vivienda: Buena. / Mala. / Intermedia.

XI Facilidades Educativas: Abundante. / Escasa. / Intermedia.

XII Calidad Educativa: Castellanizante. / Nativa-Bilingüe. / Intermedia.

XIII Atención Sanitaria: Buena. / Mala. / Intermedia.

XIV Situación legal en la posesión de tierras: Sí título. / No títuio. 


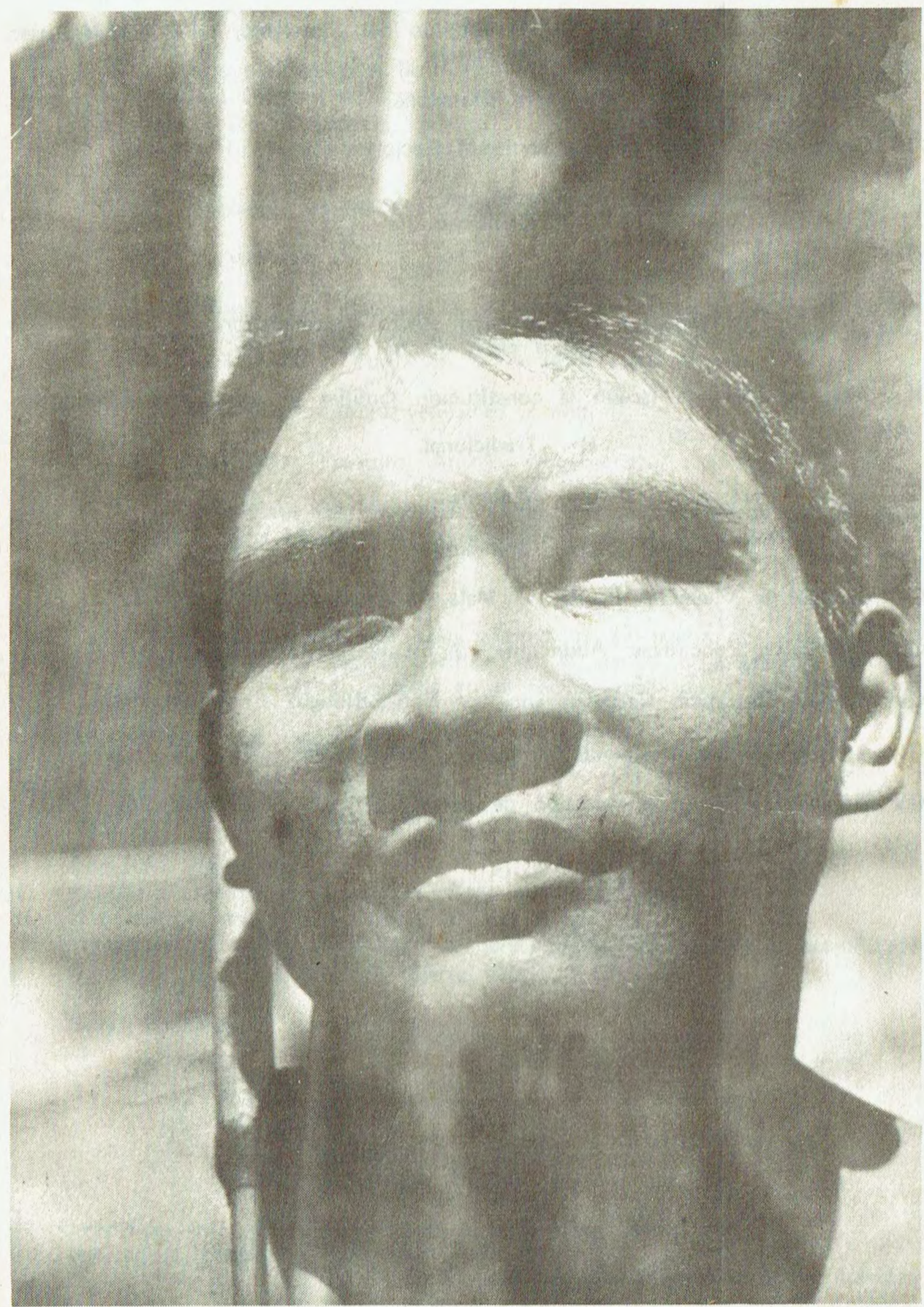

Grupo Matsés 


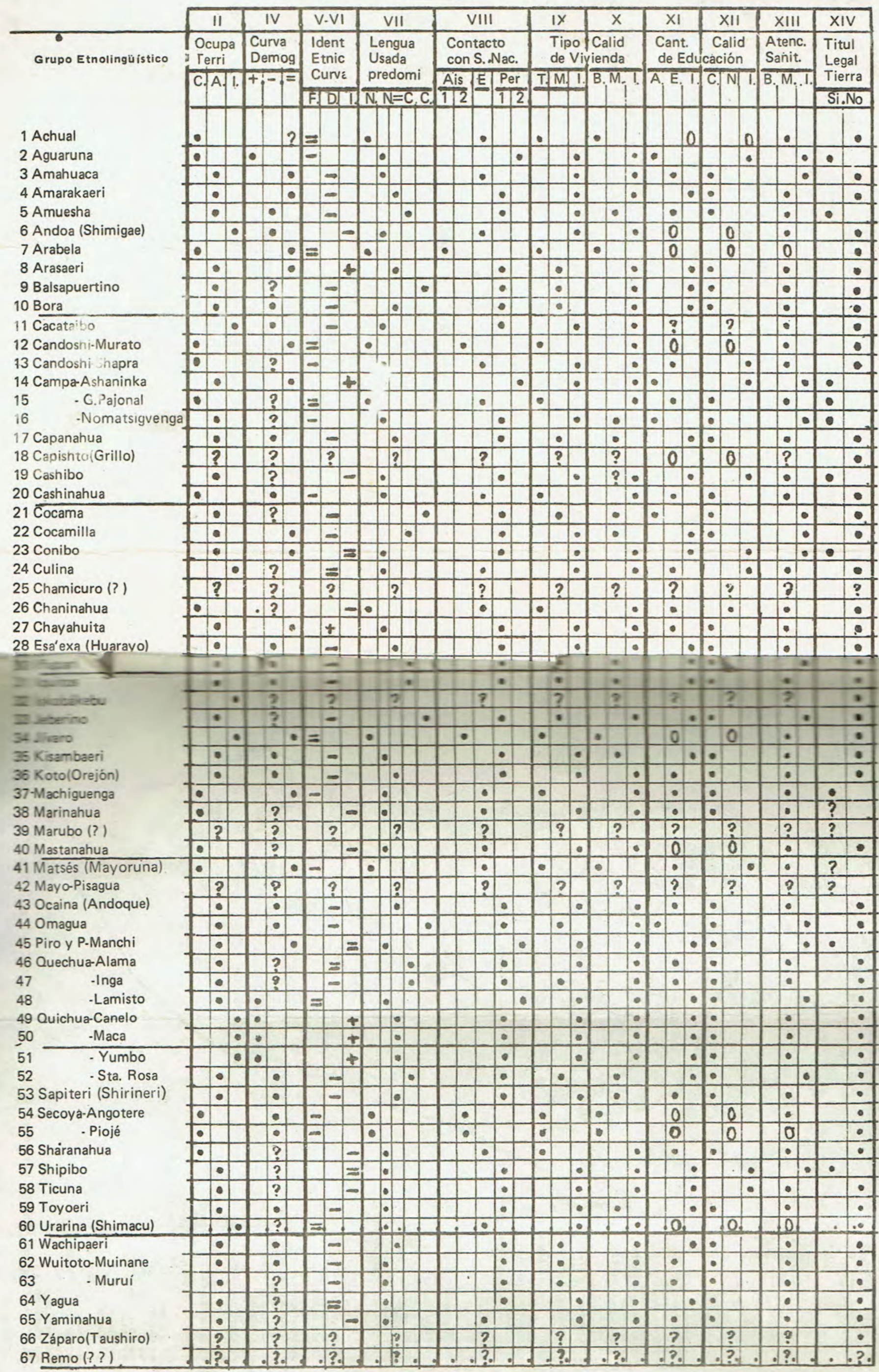


1 Achual

2. Aguaruna

3 Amahuaca

1 A Amarakaeri

i 5 Amuesha

6 Andoa (Shimigae)

7 Arabela

9 Balsapuertino

10 Bora

11 Cacataibo

12 Candoshi-Murato

13

4 (Campa)-Ashaninka

15

16

17 Capanahua

-.Gran Pajonalino

18 Capishto (Grillo)

19 Cashibo

20 (Cashinahua) Honikoin

21 Cocama

22 Cocamilla

23 Conibo

24 Culina

25 Chamicuro (?)

26 Chaninahua

27 Chayahuita

28 Esa'exa (Huarayo)

29 Huambisa

30 Inapari

31 iquito

32 iskobákebu (I sconahua)

33 Jeberino

34 Jivaro

35 Kisambaeri

36 Koto (Orejon)

37 Machiguenga

38 Marinahua

39 Marubo (?)

40 Mastanahua

41 Matses (Mayoruna)

42 Mayo-Pisagua (?)

43 Ocaina (Andoque)

44 Omagua

45 Piroy Piro-Manchineri

46 Quechua-Alama (Pastaza)

$47 \quad$ - Lamisto (S. Martín)

49 Quichua-Canelo (Napo)

50 , Maca (Napo)

51 Vumbo (Napo)

52 "Santarrosino (Madre de Dios)

53 sapiteri (Sirineri)

ta secoya-Angotere

55 aioje

56 sharanahua

67 shipibo

bi Tieuna

56 Toyoeri

60 Urarina (Shimaeu, Cimarrón)

61 Wuachisaer

62 Witete Huinane

63

6 A Yagua

65 Yaminahua

66 Zaparo (Taushiro, Aushiri, Vacacocha)
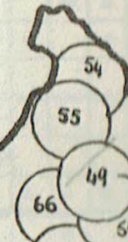

7

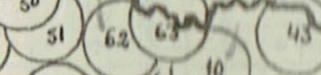

3101010

Iaviros 64

0

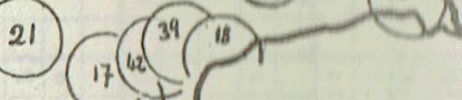

2

29

13

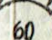

27)

- $<0$

14) 21
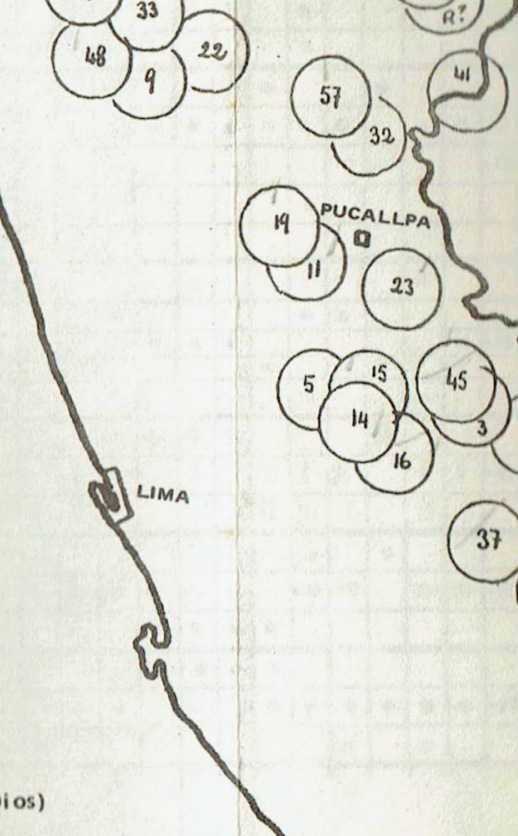

23
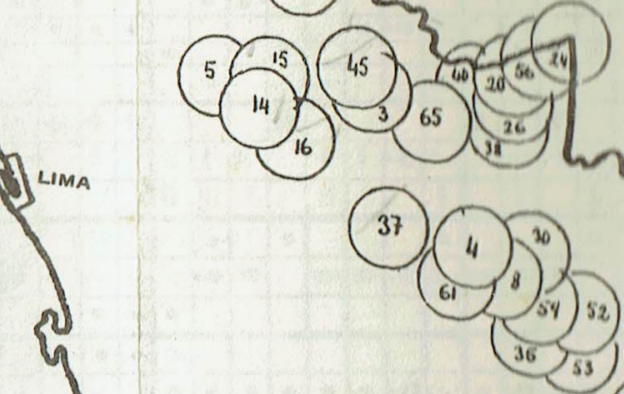

28

67 Remo (?) 


\section{EPILOGO}

Para finalizar el presente informe, estimo conveniente destacar algunas de las conclusiones que se derivan directamente de los datos $y$ clasificaciones sintetizados en el Anexo I y las catorce columnas que lo integran (39).

1. Por lo que se refiere a la columna de Ocupación Territorial encontramos lo siguiente: el 22.39 o/o de los grupos entran en la categoría de "compacto" (Cfr. Anexo I Columna II "C"). El 53.73 o/o de los Grupos entran .en la categoría de "atomizado" (Cfr. Anexo, Col II "A"). El 14.93 o/o estarian en la situación "intermedia" (Cfr. Anexo, Col. II, "I"). Finalmente encontramos un 8.95 o/o de Grupos Tribales no clasificados por carecer de datos y aparecen en el Anexo, Columna II con un signo de interrogación (40).

2. Dada la falta de censos adecuados, la Columna IV que clasifica la Tendencia de la Curva Demográfica es altamente tentativa. Parece ser que el 7.46 o/o muestra tendencia al crecimiento demográfico ( $\mathrm{frr}$. Anexo, Col. IV, + ) El 29.85 o/o de los Grupos tiende a decrecer (Cfr. An., Col. IV, -). El 20.90 o/o presentaría una situación de estabilidad demográfica (Cfr. An., Col. IV, =). Pero hay que hacer notar que del 41.79 o/o de los grupos carecemos totalmente de datos para clasificarlos $y$ aparecen en el Anexo con un signo de interrogación.

3. Por lo que se refiere al Grado de Identificación Etnica, parecen deducirse las conclusiones siguientes: el 22.39 o/o de los Grupos presenta todavia una identidad y autoestima étnica "fuerte" (cfr. An., Col V, "F"). Por el contrario el 41.79 o/o aparece como "débil" (Cfr. An., Col. V “D”). El 25.37 o/o de los Grupos presentan una situación “intermedia” (Cfr. An., Col. V, " $\mid$ "). $Y$ del 10.45 o/o restantes carecemos de datos para clasificarlos.

4. La clasificación al evaluar la Tendencia en la Identificación y Autoestima Et nica, es también altamente tentativa por carecer de estudios sincrónicos (mucho menos diacrónicos de la mayoría de las Etnias Amazónicas). Sin embargo la situación parece ser la siguiente: en un 8.96 o/o de los grupos la identidad y autoestima étnica muestra tendencia a "fortalecerse" (Cfr. An. Col. VI, + l: En 59.70 o/o por el contrario tiende a "debilitarse" (Cfr. An., Col. VI, -) . Un 20.90 o/o parece presentar una situación “estabilizada”(Cfr. An., Col. VI, =). Finalmente del 10.44 o/o de los Grupos restantes carecemos de datos para hacer una clasificación educadamente tentativa (Cfr. An., Col. VI, ?).

5. En la Columna del Uso de la Lengua, por las diferentes comunidades parlantes encontramos lo siguiente: el 14.93 o/o de los Grupos Etnolingüísticos emplea exclusivamente la lengua nativa (Cfr. An., Col. VII, "N"). El 41.79 /o usan ambas lenguas pero con claro predominio de la nativa (Cgr. An., Col. VII, "N/C"), Un 17.91 por ciento también esarían ambas lenguas, pero

Para ver las definiciones y criterios que respaidan la clasificación y/o evaluaciónaqui presentada, remitimos a la descripción de las 14 categorias presentadas anteriormente (págs. 36 - 39) 
sin claro predominio de ninguna de ellas (Cfr. An., Col VII, "N= C"). EI 10.45 o/o de los Grupos también usan ambas lenguas, pero con amplio predominio del castellano sobre la lengua nativa (Cfr. An., Col. VII, "C/N"). Finalmente sólo un 5.97 o/o emplea exclusivamente el castellano (Cfr. An., Col. VII, "C"'). Y nos resta un 8.95 o/o de los grupos, no clasificados, por carecer de datos.

6. La situación de los Grupos según El Grado de Contacto con la sociedad envolvente $y$ dominante es la siguiente: el 2.99 o/o de los Grupos se encontraría en situación de aislamiento pre-contacto (Cfr. An. VIII, Ais. 1).Un 5.97 o o también en situación de aislamiento, pero post-contacto (Cfr. An., VIII, Ais. 2). En contacto esporádico, sin embargo encontramos al $22.39 \mathrm{o} / \mathrm{o}$ de los grupos (Cfr. An., Col. VIII, "E"). En contacto permanente y desintegrador un 53.73 o/o (Cfr. An., Col. VIII, Per. 1). $Y$ encontramos un 5.97 o/o de grupos en situación de contacto permanente aunque no claramente desintegrador (Cfr. An. Col. VIII, Per. 2). Finalmente, carecemos de datos para clasificar el 8.95 o/o de los Grupos restantes (Cfr. An., Col VIII, ?).

7. El Tipo de Vivienda, según la constitución familiar y la construcción, presenta el siguiente panorama: el 19.40 o/o de los Grupos es clasificadocomo "tradicional" (Cfr. An., Col IX, "T"). El 20.90 o/o por el contrario es clasificado como "moderno"(Cfr. An., Col IX, "M"). El 50.75 o/o presenta una situación "intermedia" (Cfr. An., Col. IX, "l"). Finalmente carecemos de datos para poder evaluar al 8.95 o/o de los grupos (Cfr. An., Col IX, ?).

8. Por lo que se refiere a la Calidad de la Vivienda encontramos que el 8.95 \% de los grupos es clasificado como habitando una vivienda "buena" Y funcional para la región amazónica (Cfr. An., Col X, "B"). Por el contrario un 16.42 o/o como "mala" e inadecuada (Cfr. An., Col $X$, "M"). Y el 64.18 \% se encontraría en situación intermedia (Cfr. An., Col. X, "I"). Fi. nalmente carecemos de datos para clasificar el 10.45 o/o de los restantes.

9. Con referencia a las Facilidades Educativas (solamente en su aspecto cuantitativo) constatamos el panorama siguiente: solamente un $8.95 \%$ de los Grupos parece disfrutar de facilidades educativas abundantes $\mathrm{y}$ adecuadas ( $\mathrm{fr}$. An., Col XI, "B"). El 29.85 o/o muestra una situación inadecuada (Cfr. An., Col. $\mathrm{XI}$, " $\mathrm{M}$ "). EI 35.83 o $/ \mathrm{o}$ de los grupos presenta una situación intermedia (Cfr. An., Col IX, "I"). Y un 14.92 o/o de los grupos carecen totalmente de facilidades educativas. Finalmente, carecemos de datos para evaluar el $10.45 \%$ de los grupos restantes.

10. Al analizar la Calidad Educativa el panorama es el siguiente: un 59.71 o/o de los grupos está sometido a una educación "castellanizante" y desintegradora (Cfr. An., Col XII, "C"). No hay un sólo grupo que disfrute de una educación nativa auctóctona y adaptada (Cfr. An., Col XII, "N"). Encontramos un 14.92 o/o de los grupos que disfruta de una educación "interme -

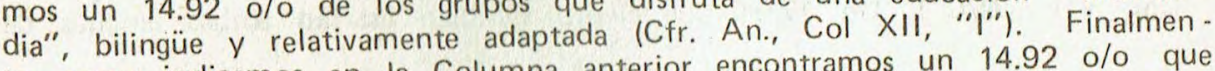
te, como indicamos en la Columna anterior encontramos un 14.92 o/o que carecen totalmente de facilidades educativas $\mathrm{v}$ el $10.45 \mathrm{o} /$ o restante no clasificado por carecer de datos.

11.La situación por lo que se refiere a la Atención Sanitaria de los Grupos parece ser la siguiente: no encontramos un sólo grupo que disfrute de una 
atención suficiente $\mathrm{V}$ adecuada (Cfr. An., Col. XIII, "B"). Por el contrario, encontramos que del 62.68 o/o aparece en la categoría mala, inadecuada (Cfr. An., Col. XIII, "M"). Un 22.39 o/o de los grupos está ubicado en la categoría de atención sanitaria "intermedia" (Cfr. An., Col. XIII, "I") y un 4.48 o/o de los grupos carece en absoluto de atención sanitaria. Finalmente, carecemos de datos para evaluar la situación del 10.45 o/o de los Grupos restantes (Cfr. An., Col. XIII, ?).

12. No nos restaría sino sintetizar la situación en lo que se refiere a la Tenencia legal de la Tierra: solamente el 16.42 o/o de los Grupos posee título legal de las tierras que habita (Cfr. An., Col XIV, "Si"). En cambio el 74.63 o/o carece de título (Cfr. An., Col XIV, "NO"). Carecemos de datos para clasificar el 8.95 o/o restante aunque se puede asumir que carecen también de título legal ya que de lo contrario deberían aparecer en la documentación oficial, no siendo este el caso.

\section{CONCLUSION}

Expresa y conscientemente dejo fuera de este informe el análisis y/o interpretación de los datos presentados. Ello será materia de un proxımo trabajo.

Comparativamente hablando, la situación de los Indígenas Amazónicos en Perú, es menos injusta, deperimente y/o desesperada que en otros países vecinos. Por parte del Gobierno - desde la promulgación de la Ley de Comunidades Nạ tivas y Desarrollo Agropecuario de la Selva, el 24 de junio de 1974- a pesar de las limitaciones y contradicciones de la Ley misma, más aún de su implementación (41), se percibe una política más favorable hacia los Grupos Tribales de la Amazonía. También se perciben indicios por parte de algunos miembros de ciertos frentes de expansión cultural (particularmente algunos misioneros) de un mayor respeto cultural y conocimientos de tales Grupos. Así mismo, están apareciendo algunos científicos sociales más comprometidos (no sólo teóricamente) con las poblaciones Indigenas.

A pesar de tales hechos, es alarmante y urgente la situación "tierras", (donde el 74.63 o/o y posiblemente el 83.58 o/o de los grupos no poseen título legal) $\mathrm{y}$ donde el 53.73 o/o de los grupos ocupan un territorio atomizado e in filtrado; también requiere medidas de emergencia la situación de "atención sanitaria", donde el 62.68 o/o de los grupos sólo dispone de una atención mala, insuficiente $y$ el 4.48 o/o - posiblemente el 14.93 o/o- carece totalmente de atención; así como el hecho de que un 53.73 o/o de los grupos se encuentra en una situación de contacto permanente $\mathrm{v}$ desintegrador con los diferentes segmentos sociales de la comunidad nacional, siendo lo anterior tanto más alarmante cuando dicho contacto no hará sino aumentarse e intensificarse en el futuro; y que el $29.85 \%$ de los grupos tienda a decrecer demográficamente; tampoco es muy favorable el hecho de que el 59.71 o/o de los grupos estë: sometido a una educación castellanizante y desintegradora; y finalmente (por no mencionar todos los factores) también es dolorsamente significativo el dato de que el $41.79 \mathrm{o} / \mathrm{o}$

(41) Cfr. L. M. Uriarte 1974: "En torno a la ley de Selva", CEAS, Lima. 
de los grupos exhiba una identidad y autoestima étnica débil, lo que es peor aún, que el 59.70 o/o de los grupos manifieste una tendencia clara hacia la debilitación y desintegración de la misma.

Ante las presiones actuales - que no harán sino aumentar- de los frentes de expansión tanto económico (extractivistas, ganadero, agrícola y mercantil), como político y cultural, se requieren tres medidas de absoluta emergencia para que las Etnias-Nativas sobrevivan: primero, la adjudicación legal de tierras (suficiente en extensión $\gamma$ calidad para el crecimiento demográfico) y en forma contigua, no atomizada en comunidades, con infiltración de no-nativos. Segundo, atención médica urgente de tuberculosis, anemia y enfermedades venéreas para los grupos ya en contacto; medidas profilácticas para los grupos aislados; y medidas antiparasitarias para todos. Tercero, fomentar -o al menos, permitir- una conciencia étnica manifestada en formas de organización política, tanto a nivel intra-tribal como inter-tribal. Para ello es indispensable alentar - o al menos permitir- la formación de una Federación (o equivalente) Indígena, específica de ellos, dirigida por ellos e integrada por todas las Etnias Tribales de la Amazonía Peruana.

Finalmente, es en este contexto que debo mencionar (no elaborar, que será materia de otro trabajo) un serio peligro. Afirmar, como se ha hecho (42),"... qúe en el Perú ya no hay Indios, sólo campesinos ...", organizar Ligas Agra rias (43) inter-étnicas (incluyendo colonos y nativos, cuyos intereses en la Amazonía son no solamente diversos sino antagónicos) y Federaciones Departamentales bajo la "pirámide" de la. Confederación Nacional Agraria (CNA), considero que es la política más eficaz para impedir una verdadera Federación Indigena y para negar desde su misma raiz la existencia de los Grupos Etnicos con identidad e intereses propios especificos en la Amazonía Peruana. (42) Discurso del Gral. Velasco Alvarado, Presidente del Gobierno Revolucionario de las
F. A. del Perú, Julio 1975 . 